Gregory A. Masters, Helen F. Graham

Cancer Center, Newark, DE; Sarah Temin American Society of Clinical Oncology, Alexandria; Sherman Baker Jr, Virginia Commonwealth University; David Trent Virginia Cancer Center, Richmond, VA; Christopher G. Azzoli, Massachusetts General Hospital Cancer Center, Boston, MA; Giuseppe Giaccone, Lombardi Cancer Center, Georgetown University, Washington, DC; Julie R. Brahmer and Thomas J. Smith, Sidney Kimmel Comprehensive Cancer Center, Johns Hopkins, Baltimore, MD: Peter M. Ellis, Juravinski Cancer Centre, Hamilton, Ontario, Canada; Ajeet Gaira, Upstate Medical University, Syracuse, NY; Nancy Rackear, Uniting Against Lung Cancer, Fort Lauderdale, FL; Joan $\mathrm{H}$. Schiller, University of Texas Southwestern; David H. Johnson, University of Texas Southwestern Medical Center at Dallas, Dallas; and John R. Strawn, patient representative, Houston, TX

Published online ahead of print at www.jco.org on August 31, 2015.

Clinical Practice Guideline Committee approval: February 27, 2015

Editor's note: This American Society of Clinical Oncology clinical practice guideline provides recommendations, with comprehensive review and analyses of the relevant literature for each recommendation. Additional information, including a Data Supplement with additional evidence tables, a Methodology Supplement, slide sets, and clinical tools and resources, is available at http://www.asco.org/guidelines/nsclc; links to patient information can be found at http://www.cancer.net.

Reprint requests: American Society of Clinical Oncology, 2318 Mill Rd, Suite 800, Alexandria, VA 22314; e-mail: guidelines@asco.org.

Authors' disclosures of potential conflicts of interest are found in the article online at www.jco.org. Author contributions are

found at the end of this article.

C 2015 by American Society of Clinica Oncology

Corresponding author: American Society of Clinical Oncology, 2318 Mill Rd, Suite 800, Alexandria, VA 22314

e-mail: guidelines@asco.org.

() 2015 by American Society of Clinical Oncology

0732-183X/15/3330w-3488w/\$20.00

DOI: $10.1200 / J C O .2015 .62 .1342$

\title{
Systemic Therapy for Stage IV Non-Small-Cell Lung Cancer: American Society of Clinical Oncology Clinical Practice Guideline Update
}

\author{
Gregory A. Masters, Sarah Temin, Christopher G. Azzoli, Giuseppe Giaccone, Sherman Baker Jr, \\ Julie R. Brahmer, Peter M. Ellis, Ajeet Gajra, Nancy Rackear, Joan H. Schiller, Thomas J. Smith, \\ John R. Strawn, David Trent, and David H. Johnson
}

See accompanying article on page 3447

$\begin{array}{llllllll}\text { A } & \text { B } & \text { S } & \text { T } & \text { R } & \text { A } & \text { C } & \text { T }\end{array}$

\section{Purpose}

To provide evidence-based recommendations to update the American Society of Clinical Oncology guideline on systemic therapy for stage IV non-small-cell lung cancer (NSCLC).

\section{Methods}

An Update Committee of the American Society of Clinical Oncology NSCLC Expert Panel based recommendations on a systematic review of randomized controlled trials from January 2007 to February 2014.

\section{Results}

This guideline update reflects changes in evidence since the previous guideline.

\section{Recommendations}

There is no cure for patients with stage IV NSCLC. For patients with performance status (PS) 0 to 1 (and appropriate patient cases with PS 2) and without an EGFR-sensitizing mutation or ALK gene rearrangement, combination cytotoxic chemotherapy is recommended, guided by histology, with early concurrent palliative care. Recommendations for patients in the first-line setting include platinum-doublet therapy for those with PS 0 to 1 (bevacizumab may be added to carboplatin plus paclitaxel if no contraindications); combination or single-agent chemotherapy or palliative care alone for those with PS 2; afatinib, erlotinib, or gefitinib for those with sensitizing EGFR mutations; crizotinib for those with ALK or ROS1 gene rearrangement; and following first-line recommendations or using platinum plus etoposide for those with large-cell neuroendocrine carcinoma. Maintenance therapy includes pemetrexed continuation for patients with stable disease or response to first-line pemetrexed-containing regimens, alternative chemotherapy, or a chemotherapy break. In the second-line setting, recommendations include docetaxel, erlotinib, gefitinib, or pemetrexed for patients with nonsquamous cell carcinoma; docetaxel, erlotinib, or gefitinib for those with squamous cell carcinoma; and chemotherapy or ceritinib for those with $A L K$ rearrangement who experience progression after crizotinib. In the third-line setting, for patients who have not received erlotinib or gefitinib, treatment with erlotinib is recommended. There are insufficient data to recommend routine third-line cytotoxic therapy. Decisions regarding systemic therapy should not be made based on age alone. Additional information can be found at http://www.asco.org/guidelines/nsclc and http://www.asco.org/guidelineswiki.

\section{J Clin Oncol 33:3488-3515. (C) 2015 by American Society of Clinical Oncology}

\section{INTRODUCTION}

The purpose of this guideline update is to revise the American Society of Clinical Oncology (ASCO) guideline on the systemic treatment of patients with stage IV non-small-cell lung cancer (NSCLC). The full ASCO clinical practice guideline update on chemotherapy for stage IV NSCLC was last published in 2009. ${ }^{1}$ A focused update on switch maintenance was published in $2011 .^{2}$ Since the 2009 guideline, the understanding of histologic and molecular subtypes of NSCLC has increased, and as a result, the clinical questions have been reformulated for presentation in terms of histology and molecular subtype.

This update includes 73 phase III randomized controlled trials (RCTs) on systemic therapy. It reviews and analyzes new and updated evidence, including data regarding afatinib, ceritinib, crizotinib, erlotinib, continuation maintenance, and switch maintenance. 


\section{Recommendations for Systemic Treatment of Patients With Stage IV Non-Small-Cell Lung Cancer: ASCO Clinical Practice Guideline Update}

\section{Guideline Question}

What systemic therapy treatment options should be offered to patients with stage IV non-small-cell lung cancer (NSCLC), depending on the subtype of the patient's cancer?

\section{Target Population}

Patients with stage IV NSCLC.

\section{Target Audience}

This clinical practice guideline update is targeted at health care providers (including medical oncologists, nurses, social workers, and any other relevant members of comprehensive multidisciplinary cancer care teams), and patients and their caregivers in North America and beyond.

\section{Methods}

An Update Committee was convened to develop clinical practice guideline recommendations based on a systematic review of the medical literature.

\section{Key Points}

See Recommendations section for full details.

- There is no cure for patients with stage IV NSCLC.

- Decisions on chemotherapy should not be made on the basis of age alone.

\section{First-Line Treatment for Patients:}

- Without an EGFR-sensitizing mutation or $A L K$ gene rearrangement and performance status (PS) 0 to 1 (or appropriate PS 2): a variety of combination cytotoxic chemotherapies are recommended. Platinum-based doublets are preferred, along with early concurrent palliative care and symptom management. Based on tumor histology (ie, squamous $v$ nonsquamous), there are some variations (evidence quality: high; strength of recommendation: strong).

- Adding bevacizumab to carboplatin plus paclitaxel is recommended if there are no contraindications (evidence quality: intermediate; strength of recommendation: moderate).

- With PS 2: combination or single-agent chemotherapy or palliative care alone may be used (chemotherapy: evidence quality: intermediate; strength of recommendation: weak; palliative care: evidence quality: intermediate; strength of recommendation: strong).

- With sensitizing EGFR mutations: afatinib, erlotinib, or gefitinib is recommended (evidence quality: high; strength of recommendation: strong for each).

- With $A L K$ gene rearrangements: crizotinib is recommended (evidence quality: high; strength of recommendation: strong).

- With ROS1 rearrangement: crizotinib is recommended (type: informal consensus; evidence quality: low; strength of recommendation: weak).

- With large-cell neuroendocrine carcinoma: platinum plus etoposide or the same treatment as other patients with nonsquamous carcinoma may be administered (type: informal consensus; evidence quality: low; strength of recommendation: weak).

- First-line cytotoxic chemotherapy should be stopped at disease progression or after four cycles in patients with nonresponsive stable disease (no change).

(continued on following page) 
- With stable disease or response after four cycles of a first-line pemetrexed-containing regimen: pemetrexed continuation maintenance may be used; if initial regimen does not contain pemetrexed, an alternative chemotherapy (switch) may be used, or a break from chemotherapy may be recommended until disease progression (addition of pemetrexed: evidence quality: intermediate; strength of recommendation: moderate).

\section{Second-Line Treatment for Patients:}

- With nonsquamous cell carcinoma (NSCC): docetaxel, erlotinib, gefitinib, or pemetrexed are acceptable (evidence quality: high; strength of recommendation: strong).

- With SCC: docetaxel, erlotinib, or gefitinib are acceptable (evidence quality: high; strength of recommendation: strong).

- With sensitizing EGFR mutations who did not respond to a first-line epidermal growth factor receptor (EGFR) tyrosine kinase inhibitor (TKI): combination cytotoxic chemotherapy is recommended for those with NSCC, as listed in under first-line treatment (type: informal consensus; evidence quality: intermediate; strength of recommendation: strong).

- With sensitizing EGFR mutations who received a first-line EGFR TKI and experienced disease progression after an initial response: may be switched to chemotherapy or another EGFR TKI as second-line therapy (type: informal consensus; evidence quality: low; strength of recommendation: weak).

- With $A L K$ rearrangement and progression after first-line crizotinib: chemotherapy or ceritinib may be offered (chemotherapy: evidence quality: high; strength of recommendation: strong; ceritinib: evidence quality: intermediate; strength of recommendation: moderate).

\section{Third-Line Treatment for Patients:}

- Who have not received erlotinib or gefitinib and have PS 0 to 3: erlotinib may be recommended.

- Data are insufficient to recommend routine third-line cytotoxic drugs.

\section{Note.}

For all recommendations, benefits outweigh harms. The type of recommendation is evidence based, except where otherwise noted. ASCO believes that cancer clinical trials are vital to inform medical decisions and improve cancer care and that all patients should have the opportunity to participate.

\section{Additional Resources}

More information, including a Data Supplement with additional evidence tables, a Methodology Supplement with information about evidence quality and strength of recommendations, slide sets, and clinical tools and resources, is available at http://www.asco.org/ guidelines/nsclc. Patient information is available at http://www.cancer.net.

Because ASCO recently published the ASCO endorsement of the International Association for the Study of Lung Cancer/College of American Pathologists molecular marker guideline, ${ }^{3}$ this guideline update will not specifically address the histologic classification or molecular pathology of NSCLC. The reader is also referred to the WHO/International Association for the Study of Lung Cancer adenocarcinoma classification ${ }^{4}$ and the ASCO palliative care provisional clinical opinion. ${ }^{5}$ The latter provides guidance regarding concurrent palliative care for patients with lung cancer.

\section{GUIDELINE QUESTIONS}

This clinical practice guideline addresses an overarching clinical question: What systemic therapy treatment options should be offered to patients with stage IV NSCLC, depending on the subtype of the patient's cancer? Subquestions include: What are the most effective firstand second-line therapies? What is the role of maintenance (both switch and continuation) therapy? What other clinical characteristics, besides the specified histologic and molecular subgroups, should affect drug selection? Is there a role for third-line therapy or beyond? A detailed list of clinical questions is provided in Data Supplement 5 (available at http://www.asco.org/guidelines/nsclc).

\section{METHODS}

\section{Guideline Update Development Process}

The Update Committee (members listed in Appendix Table A1, online only) met via teleconference and Webinar and corresponded 
through e-mail. On the basis of the consideration of the evidence, the authors were asked to contribute to the development of the guideline, provide critical review, and finalize the guideline recommendations. Members of the Update Committee were responsible for reviewing and approving the penultimate version of the guideline, which was then submitted to Journal of Clinical Oncology for editorial review and consideration for publication. All ASCO guidelines are ultimately reviewed and approved by the Update Committee and the ASCO Clinical Practice Guideline Committee before publication.

The recommendations were developed by an Update Committee with multidisciplinary representation using a systematic review of phase III RCTs and clinical experience. The PubMed database was searched for evidence reporting on outcomes of interest, published from January 2007 to February 2014 for non-switch maintenance questions and from June 2009 to February 2014 for switch maintenance questions. Articles were selected for inclusion in the systematic review of the evidence based on the following criteria: (1) population of patients with stage IV NSCLC (many trials also included patients with stage IIIB NSCLC), and (2) fully published presentations of English-language reports of phase III RCTs.

Articles were excluded from the systematic review if they were: (1) meeting abstracts not subsequently published in peer-reviewed journals (with one exception made for 2014 ASCO abstract presenting only phase III data on agent recently approved by US Food and Drug Administration [FDA] $\left.{ }^{6}\right) ;(2)$ editorials, commentaries, letters, news articles, case reports, or narrative reviews; or (3) published in a language other than English.

The guideline recommendations were crafted, in part, using the Guidelines Into Decision Support (GLIDES) methodology and accompanying BRIDGE-Wiz software (http://gem.med.yale.edu/BRIDGE-Wiz). Ratings for the type and strength of recommendation, evidence, and potential bias are provided with each recommendation (Methodology Supplement).

Detailed information about the methods used to develop this guideline update is also available in the Methodology Supplement at www.asco.org/ guidelines/nsclc, including an overview (eg, Update Committee composition, development process, and revision dates), literature search and data extraction, the recommendation development process (GLIDES and BRIDGEWiz), and quality assessment.

In some selected cases where evidence was lacking but there was a high level of agreement among the Update Committee, informal consensus was used (as noted with Recommendations).

\section{Guideline Disclaimer}

The clinical practice guideline and other guidance published herein are provided by ASCO to assist providers in clinical decision making. The information herein should not be relied on as being complete or accurate, nor should it be considered as inclusive of all proper treatments or methods of care or as a statement of the standard of care. With the rapid development of scientific knowledge, new evidence may emerge between the time information is developed and when it is published or read. The information is not continually updated and may not reflect the most recent evidence. The information addresses only the topics specifically identified herein and is not applicable to other interventions, diseases, or stages of diseases. This information does not mandate any particular course of medical care. Furthermore, the information is not intended to substitute for the independent professional judgment of the treating provider, because the information does not account for individual variation among patients. Each recommendation reflects high, moderate, or low confidence that the recommendation reflects the net effect of a given course of action. The use of words like "must," "must not," "should," and "should not" indicates that a course of action is recommended or not recommended for either most or many patients, but there is latitude for the treating physician to select other courses of action in individual cases. In all cases, the selected course of action should be considered by the treating provider in the context of treating the individual patient. Use of the information is voluntary. ASCO provides this information on an as-is basis and makes no warranty, express or implied, regarding the information. ASCO specifically disclaims any warranties of merchantability or fitness for a particular use or purpose. ASCO assumes no responsibility for any injury or damage to persons or property arising out of or related to any use of this information or for any errors or omissions.

\section{Guideline and Conflicts of Interest}

The Update Committee was assembled in accordance with the ASCO Conflicts of Interest Management Procedures for Clinical Practice Guidelines (summarized at http://www.asco.org/rwc). Members of the Update Committee completed the ASCO disclosure form, which requires disclosure of financial and other interests that are relevant to the subject matter of the guideline, including relationships with commercial entities that are reasonably likely to experience direct regulatory or commercial impact as a result of promulgation of the guideline. Categories for disclosure include employment; leadership; stock or other ownership; honoraria; consulting or advisory role; speaker's bureau; research funding; patents, royalties, other intellectual property; expert testimony; travel, accommodations, expenses; and other relationships. In accordance with these procedures, the majority of the members of the Update Committee did not disclose any such relationships.

\section{RESULTS}

A total of 87 publications concerning 73 phase III RCTs met the systematic review eligibility criteria and form the evidentiary basis for the guideline recommendations. Findings from 10 of these trials were published in multiple reports, ${ }^{7-28}$ indicated in the tables and text where appropriate. There were 51 trials in the first-line and maintenance settings, including seven trials for the treatment of patients with epidermal growth factor receptor (EGFR) mutations or increased EGFR expression. ${ }^{11,13,14,20,29-32}$ Twenty-five trials included patients with multiple histologies (including squamous cell carcinoma [SCC]). Nine trials reported specifically on patients who had stable disease or experienced response after four to six cycles (maintenance). ${ }^{7,8,33-40}$ There were 22 trials of second- and third-line therapies; two reported on the treatment of patients with $A L K$-positive tumors; none of these 22 trials required EGFR-positive test results; one study required all participants to have wild-type EGFR in their tumors ${ }^{41}$; 18 of 22 studies included some proportion of patients with SCC. As a result of FDA approval, one phase I trial that did not meet eligibility criteria was included in the evidence base. ${ }^{42,43}$

The publications identified spanned from 2007 to 2014. The primary outcome for most trials was therapeutic efficacy, either overall (OS) or progression-free survival (PFS). The primary outcome for all but two of the trials for clinical questions on first-line and maintenance settings was therapeutic efficacy, as with all of the 22 trials for clinical questions on second- and third-line therapies. Morbidity and quality of life (QoL) were the primary outcomes for two studies. ${ }^{18,44}$

\section{Study Characteristics}

Most studies had two arms and made a variety of comparisons; intervention arms usually included one to three agents. Of first-line trials of EGFR inhibitors, the percentage of participants known to have EGFR mutations was $0 \%$ to $100 \%$. In second-line trials, $0 \%$ to $70 \%$ of participants had EGFR mutations in EGFR-inhibitor studies. Seven trials in the second-line setting stipulated that participants could not have received prior EGFR tyrosine kinase inhibitors (TKIs). ${ }^{45-51}$ Characteristics of the studies and study participants are provided in the Data Supplement. 


\section{Study Quality Assessment}

Study quality was formally assessed for the RCTs directly relevant to current recommendations $s^{6,7,8,11,13-15,29,31,33,37,41,52-57}$ (Table 1). Quality assessment of studies not directly cited in support of recommendations is available in the Data Supplement. Design aspects related to the individual study quality were assessed by one reviewer, with factors such as blinding, allocation concealment, placebo control, intention to treat, and funding sources generally indicating an intermediate to high potential risk of bias for most of the identified evidence. Some factors varied between studies, lowering the comparability of the results. The Methodology Supplement provides for definitions of ratings for overall potential risk of bias.

\section{Outcomes}

Efficacy outcomes: first-line trials. Six trials reported significant differences for OS or median survival. ${ }^{7,8,19,31,52,53,55,58}$ Eighteen trials reported significant differences for PFS or time to progression (TTP). Table $2^{6-8,11,13,14,20-22,29-31,33,37,40,52-55,60}$ includes results of key outcomes, primarily OS and PFS or TTP, which were reported in selected trials. Other trials and efficacy results are reported in the Data Supplement evidence tables.

Efficacy outcomes: second-line trials. Two trials reported significant differences for OS or median survival ${ }^{41,57}$ Fifteen trials reported significant differences for PFS or TTP. ${ }^{15,34-36,41,47,49,56,57,62-67}$ Additional data regarding key outcomes of interest are reported in Table $3^{15,41,53,56,57}$ and in the Data Supplement.

Adverse events. Table $4^{7,11,13,14,20,29,33,37,52-55}$ lists selected adverse events from the first-line trials that reported them. Twenty-four trials reported significant differences. Table $5^{15,16,41,53,56,57}$ lists selected adverse events from the second-line trials that reported them. Additional studies are reported in the Data Supplement. Six trials reported significant differences.

QoL. QoL outcomes are reported in Tables 6 and 7 of Data Supplement 2 .

\section{RECOMMENDATIONS}

\section{CLINICAL QUESTION A1}

Which patients with stage IV NSCLC should be treated with chemotherapy?

\section{Recommendation A1.a}

For patients with performance status (PS) of 0 or 1 , a combination of two cytotoxic drugs is recommended. Platinum combinations are recommended over nonplatinum therapy; however, nonplatinum therapy combinations are recommended for patients who have contraindications to platinum therapy. Chemotherapy may also be used to treat selected patients with PS 2 who desire aggressive treatment after a thorough discussion of the risks and benefits of such treatment (type: evidence based, benefits outweigh harms; evidence quality: high; strength of recommendation: strong).

\section{Recommendation A1.b}

Because there is no cure for patients with stage IV NSCLC, early concomitant palliative care assistance has improved the survival and well being of patients and is therefore recommended (type: evidence based, benefits outweigh harms; evidence quality: high; strength of recommendation: strong).

Literature review update and analysis. This recommendation is supported by evidence reviewed in previous versions of this guideline and in the ASCO palliative care provisional clinical opinion. ${ }^{5}$

Clinical interpretation. Combination therapy improves outcomes for patients with PS 0 to 1 and appropriate patients with PS 2 who are willing to accept the potential risks and is therefore recommended by the Update Committee. More specific information about regimens and palliative care is provided in subsequent recommendations.

\section{CLINICAL QUESTION A2}

What is the most effective first-line therapy for patients with stage IV NSCLC with non-SCC (NSCC), negative or unknown $E G F R$-sensitizing mutation and $A L K$ gene rearrangement status, and PS 0 to 1 or possibly PS 2?

\section{Recommendation A2}

For patients who have the characteristics described in Clinical Question A2 and who have nonsquamous histology, the following options are acceptable:

- Cisplatin-based combinations (type: evidence based, benefits outweigh harms; evidence quality: high; strength of recommendation: strong)

- Cisplatin plus docetaxel (FDA-approved combination; http://www.cancer.gov)

- Cisplatin plus paclitaxel (FDA-approved combination; http://www.cancer.gov)

- Cisplatin plus pemetrexed (FDA-approved combination; http://www.cancer.gov)

- Cisplatin plus vinorelbine (FDA-approved combination; http://www.cancer.gov)

- Carboplatin-based combinations (type: evidence based, benefits outweigh harms; evidence quality: high; strength of recommendation: strong)

- Carboplatin plus albumin-bound (nab) -paclitaxel (FDAapproved combination; http://www.cancer.gov)

- Carboplatin plus paclitaxel (FDA-approved combination; http://www.cancer.gov)

- Carboplatin plus pemetrexed

- Carboplatin plus docetaxel

- Nonplatinum doublets (type: evidence based, benefits outweigh harms; evidence quality: intermediate; strength of recommendation: weak)

Literature review update and analysis. It is beyond the scope of this guideline update to review the entire evolution of cytotoxic chemotherapy for patients with stage IV NSCLC and good PS. Prior versions of this guideline simplified recommendations for a multitude of combinations with several basic principles on the basis of consistent observations or meta-analyses: Two-drug combinations were superior to single-agent therapy, platinum-based two-drug combinations were slightly superior to nonplatinum combinations in meta-analysis, and cisplatin was slightly superior in efficacy to carboplatin in meta-analysis but perhaps not worth the added toxicity in the palliative care setting. 


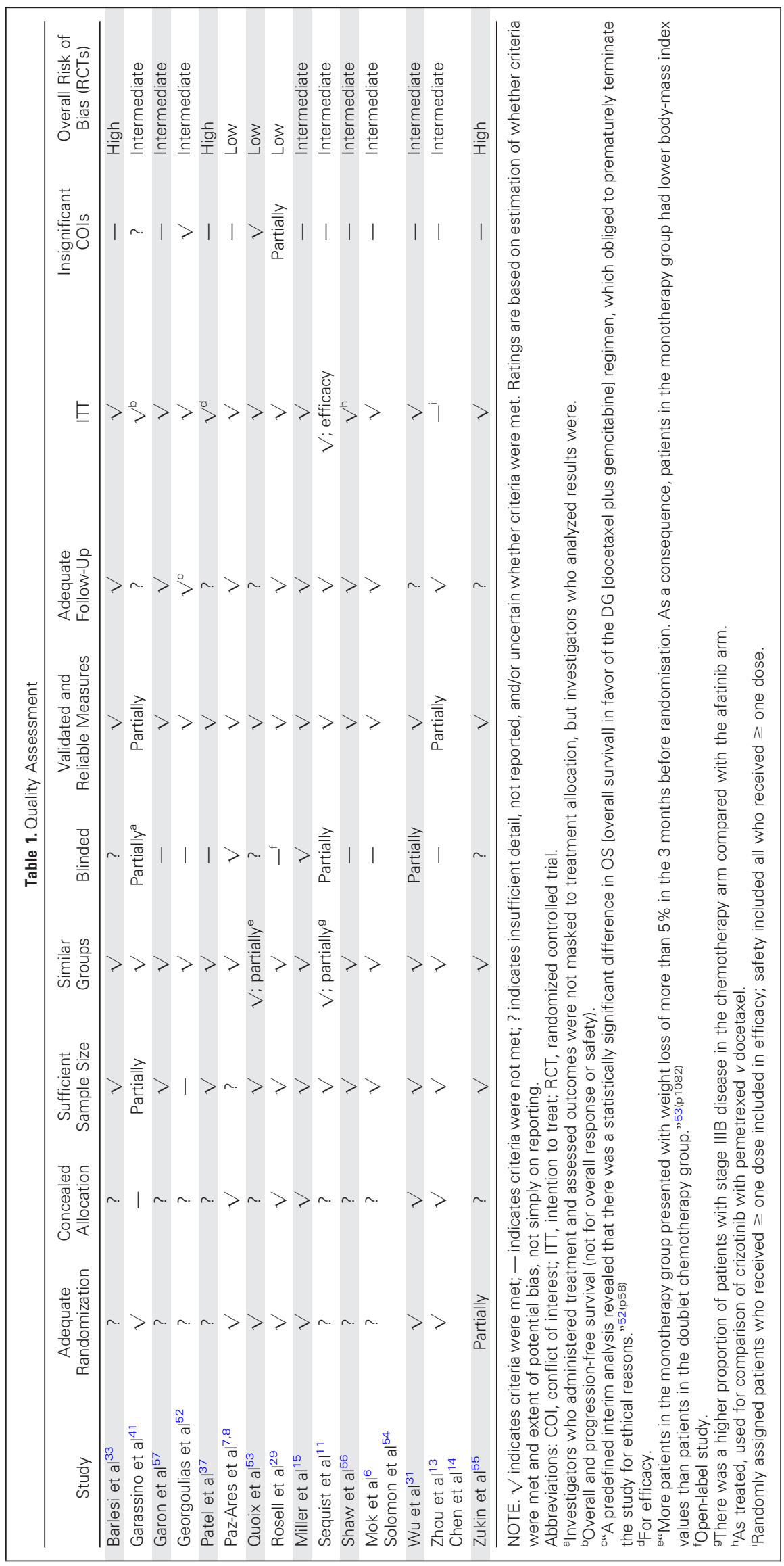




\begin{tabular}{|c|c|c|c|c|c|c|c|c|}
\hline \multirow[b]{2}{*}{ Reference } & \multirow[b]{2}{*}{ Study } & \multirow[b]{2}{*}{ Intervention } & \multirow[b]{2}{*}{ Outcome } & \multirow{2}{*}{$\begin{array}{l}\text { No. of Patients } \\
\text { Analyzed }\end{array}$} & \multirow[b]{2}{*}{ OS } & \multirow[b]{2}{*}{ PFS } & \multicolumn{2}{|c|}{$\begin{array}{l}\text { Response } \\
\text { Rate }\end{array}$} \\
\hline & & & & & & & No. & $\%$ \\
\hline \multirow[t]{2}{*}{ Rosell et al ${ }^{29}$} & Eurtac & Erlotinib & PFS/TTP & 86 & $\begin{array}{l}\text { Median, } 19.3 \text { months }(95 \% \\
\quad \mathrm{Cl}, 14.7 \text { to } 26.8 \text { ) }\end{array}$ & $\begin{array}{l}\text { Median, } 9.7 \text { months }(95 \% \\
\qquad \mathrm{Cl}, 8.4 \text { to } 12.3)\end{array}$ & 48 & $56^{a}$ \\
\hline & & Standard chemotherapy & & 87 & $\begin{array}{l}\text { Median, } 19.5 \text { months ( } 95 \% \\
\text { Cl, } 16.1 \text { to not } \\
\text { assessable) }\end{array}$ & $\begin{array}{l}\text { Median, } 5.2 \text { months ( } 95 \% \\
\quad \mathrm{Cl}, 4.5 \text { to } 5.8)\end{array}$ & 13 & $15^{\mathrm{a}}$ \\
\hline $\begin{array}{l}\text { Statistics and } \\
\text { significance }\end{array}$ & & & & & $\begin{array}{l}\mathrm{HR}, 1.04(95 \% \mathrm{Cl}, 0.65 \text { to } \\
\quad 1.68 ; P=.87)\end{array}$ & $\begin{array}{l}\mathrm{HR}, 0.37(95 \% \mathrm{Cl}, 0.25 \text { to } \\
\quad 0.54 ; P<.001)\end{array}$ & & \\
\hline \multirow[t]{2}{*}{ Quoix et al $\left.\right|^{53}$} & & $\begin{array}{l}\text { Four cycles carboplatin } \\
\text { plus taxol }\end{array}$ & $\mathrm{OS}^{\mathrm{b}}$ & $\begin{array}{l}226 \text { (144 received } \\
\text { second line) }\end{array}$ & $\begin{array}{l}\text { Median, } 10.3 \text { months }(95 \% \\
\quad \mathrm{Cl}, 8.3 \text { to } 12.6)\end{array}$ & $\begin{array}{l}\text { Median, } 6 \text { months }(95 \% \\
\mathrm{Cl}, 5.5 \text { to } 6.8)\end{array}$ & NR & 27.1 \\
\hline & & $\begin{array}{l}\text { Five cycles vinorelbine } \\
\text { or gemcitabine }\end{array}$ & & $\begin{array}{l}225 \text { (145 received } \\
\text { second line) }\end{array}$ & $\begin{array}{l}\text { Median, } 6.2 \text { months }(95 \% \\
\quad \mathrm{Cl}, 5.3 \text { to } 7.3 \text { ) }\end{array}$ & $\begin{array}{l}\text { Median, } 2.8 \text { months }(95 \% \\
\quad \mathrm{Cl}, 2.6 \text { to } 3.7)\end{array}$ & NR & 10.2 \\
\hline $\begin{array}{l}\text { Statistics and } \\
\text { significance }\end{array}$ & & & & & $\begin{array}{l}\mathrm{HR}, 0.64(95 \% \mathrm{Cl}, 0.52 \text { to } \\
\quad 0.78 ; P<.001)\end{array}$ & $P<.001$ & $P<$ & $.001^{\mathrm{c}}$ \\
\hline $\begin{array}{l}\text { Maemondo et } \mathrm{al}^{20} \\
\text { Inoue et } \mathrm{al}^{21}\end{array}$ & $\begin{array}{l}\text { Maemondo (see EGFR } \\
\quad \text { PCO }^{59} \text { ) }\end{array}$ & Gefitinib & $\mathrm{PFS} / \mathrm{TTP}$ & $\begin{array}{l}\text { ITT, 114; PFS, 114; } \\
\text { OoL, } 72\end{array}$ & Median, 27.7 months & Median, 10.8 months & 84 & 73.7 \\
\hline Oizumi et $\mathrm{al}^{22}$ & & $\begin{array}{l}\text { Carboplatin plus } \\
\text { paclitaxel }\end{array}$ & & $\begin{array}{l}\text { ITT, 114; PFS, 110; } \\
\text { QoL, } 76\end{array}$ & Median, 26.6 months & Median, 5.4 months & 35 & 30.7 \\
\hline $\begin{array}{l}\text { Statistics and } \\
\text { significance }\end{array}$ & & & & $\begin{array}{l}\text { ITT, } 228^{\text {d. }} \text { PFS, 214; } \\
\text { QoL, } 148\end{array}$ & $\mathrm{HR}, 0.887(P=.483)$ & $\begin{array}{l}\mathrm{HR}, 0.32(95 \% \mathrm{Cl}, 0.24 \text { to } \\
\quad 0.44 ; P<.001)^{\mathrm{e}}\end{array}$ & $P<$ & .001 \\
\hline \multirow[t]{2}{*}{ Georgoulias et $\mathrm{al}^{52}$} & & $\begin{array}{l}\text { Docetaxel and } \\
\text { gemcitabine }\end{array}$ & OS & 157 & $\begin{array}{l}\text { Median, } 9.4 \text { months }(95 \% \\
\quad \mathrm{Cl}, 0.5 \text { to } 52.7)\end{array}$ & $\begin{array}{l}\text { Median, } 3.5 \text { months }(95 \% \\
\quad \mathrm{Cl}, 0.5 \text { to } 40.1)\end{array}$ & 42 & 26.8 \\
\hline & & Docetaxel & & $155^{\dagger}$ & $\begin{array}{l}\text { Median, } 8.3 \text { months }(95 \% \\
\quad \mathrm{Cl}, 0.5 \text { to } 41.4)\end{array}$ & $\begin{array}{l}\text { Median, } 2.3 \text { months }(95 \% \\
\quad \mathrm{Cl}, 0.5 \text { to } 35.8)\end{array}$ & 18 & 11.6 \\
\hline $\begin{array}{l}\text { Statistics and } \\
\text { significance }\end{array}$ & & & & & Log-rank $P=.037^{\mathrm{g}}$ & Log-rank $P=.054^{\mathrm{h}}$ & $P<$ & .001 \\
\hline \multirow[t]{2}{*}{ Patel et $\mathrm{al}^{37}$} & PointBreak & $\begin{array}{l}\text { Pemetrexed, carboplatin, } \\
\text { and bevacizumab } \\
\text { followed by } \\
\text { pemetrexed plus } \\
\text { bevacizumab }\end{array}$ & OS & 472 & $\begin{array}{l}\text { Median, } 12.6 \text { months (95\% } \\
\quad \mathrm{Cl}, 11.3 \text { to } 14.0)\end{array}$ & $\begin{array}{l}\text { Median, } 6 \text { months }(95 \% \\
\text { Cl, } 5.6 \text { to } 6.9)\end{array}$ & NR & 34.1 \\
\hline & & $\begin{array}{l}\text { Paclitaxel, carboplatin, } \\
\text { and bevacizumab } \\
\text { followed by } \\
\text { bevacizumab }\end{array}$ & & 467 & $\begin{array}{l}\text { Median, } 13.4 \text { months }(95 \% \\
\quad \mathrm{Cl}, 11.9 \text { to } 14.9)\end{array}$ & $\begin{array}{l}\text { Median, } 5.6 \text { months }(95 \% \\
\quad \mathrm{Cl}, 5.4 \text { to } 6.0)\end{array}$ & NR & 33.0 \\
\hline $\begin{array}{l}\text { Statistics and } \\
\text { significance }\end{array}$ & & & & & $\begin{array}{l}\mathrm{HR}, 1.00(95 \% \mathrm{Cl}, 0.86 \text { to } \\
\quad 1.16 ; P=.949)\end{array}$ & $\begin{array}{l}\mathrm{HR}, 0.83(95 \% \mathrm{Cl}, 0.71 \text { to } \\
\quad 0.96 ; P=.012)\end{array}$ & & \\
\hline \multirow[t]{2}{*}{ Barlesi et al ${ }^{33}$} & AVAPERL & $\begin{array}{l}\text { Maintenance } \\
\text { bevacizumab } 7.5 \mathrm{mg} / \\
\text { kg }\end{array}$ & PFS/TTP & 128 & $\begin{array}{l}\text { From random assignment: } \\
\text { median, } 12.8 \text { months } \\
\text { (range, } 0 \text { to } 16 \text { ); from } \\
\text { time of first induction: } \\
\text { median, } 15.7 \text { months } \\
\text { (range, } 2.8 \text { to } 18.8 \text { ) }\end{array}$ & Median, 3.7 months & NR & 50.0 \\
\hline & & $\begin{array}{l}\text { Bevacizumab } 7.5 \mathrm{mg} / \mathrm{kg} \\
\text { plus pemetrexed } 500 \\
\mathrm{mg} / \mathrm{m}^{2}\end{array}$ & & 125 & $\begin{array}{l}\text { From time of first } \\
\text { induction: not yet } \\
\text { reached (range, } 3.0 \text { to } \\
\text { 19) }\end{array}$ & Median, 7.4 months & $N R^{j}$ & 55.5 \\
\hline $\begin{array}{l}\text { Statistics and } \\
\text { significance }\end{array}$ & & & & & & $\begin{array}{l}\mathrm{HR}, 0.48(95 \% \mathrm{Cl}, 0.35 \text { to } \\
\quad 0.66 ; P<.001)\end{array}$ & & \\
\hline \multirow[t]{2}{*}{ Paz-Ares et al ${ }^{7,8}$} & PARAMOUNT & $\begin{array}{l}\text { Pemetrexed plus } \\
\text { cisplatin induction } \\
\text { and maintenance } \\
\text { pemetrexed }\end{array}$ & $\begin{array}{l}\text { PFS/TTP; PFS of } \\
\text { maintenance } \\
\text { arms }\end{array}$ & 359 & $\begin{array}{l}\text { Median, } 13.9 \text { months }(95 \% \\
\quad \mathrm{Cl}, 12.8 \text { to } 16.0 \text { ) }\end{array}$ & $\begin{array}{l}\text { Median, } 4.4 \text { months }(95 \% \\
\qquad \mathrm{Cl}, 4.1 \text { to } 5.7)^{\mathrm{k}}\end{array}$ & \multirow{3}{*}{\multicolumn{2}{|c|}{$\begin{array}{l}\text { Overall: } n \\
\quad=9 \\
\text { (3\%) of } \\
316\end{array}$}} \\
\hline & & $\begin{array}{l}\text { Pemetrexed plus } \\
\text { cisplatin induction } \\
\text { and placebo }\end{array}$ & & 180 & $\begin{array}{l}\text { Median, } 11 \text { months }(95 \% \\
\quad \mathrm{Cl}, 10.0 \text { to } 12.5)\end{array}$ & $\begin{array}{l}\text { Median, } 2.8 \text { months }(95 \% \\
\qquad \mathrm{Cl}, 2.6 \text { to } 3.0)\end{array}$ & & \\
\hline $\begin{array}{l}\text { Statistics and } \\
\text { significance }\end{array}$ & & & & & $\begin{array}{l}\text { Unadjusted } \mathrm{HR}, 0.78(95 \% \\
\qquad \mathrm{Cl}, 0.64 \text { to } 0.96 \text {; log- } \\
\text { rank } P=.019)\end{array}$ & $\begin{array}{l}\mathrm{HR}, 0.60(95 \% \mathrm{Cl}, 0.50 \text { to } \\
\quad 0.73 ; P<.001)^{7}\end{array}$ & & \\
\hline & & & (continued on & following page) & & & & \\
\hline
\end{tabular}

In the interest of clarity, the Update Committee decided to list acceptable regimens on the basis of the new evidence. In the past 10 years, major findings influencing the selection of first-line chemother- apy include that addition of bevacizumab to carboplatin and paclitaxel improves OS in select patients with NSCC and that the combination of cisplatin and pemetrexed is superior to that of cisplatin and 


\begin{tabular}{|c|c|c|c|c|c|c|c|c|}
\hline \multirow[b]{2}{*}{ Reference } & \multirow[b]{2}{*}{ Study } & \multirow[b]{2}{*}{ Intervention } & \multirow[b]{2}{*}{ Outcome } & \multirow{2}{*}{$\begin{array}{l}\text { No. of } \\
\text { Patients } \\
\text { Analyzed }\end{array}$} & \multirow[b]{2}{*}{ OS } & \multirow[b]{2}{*}{ PFS } & \multicolumn{2}{|c|}{$\begin{array}{l}\text { Response } \\
\text { Rate }\end{array}$} \\
\hline & & & & & & & No. & $\%$ \\
\hline \multirow[t]{2}{*}{$\overline{\text { Wu et al }}{ }^{31}$} & FASTACT-2 & $\begin{array}{l}\text { Chemotherapy plus } \\
\text { erlotinib (intercalated } \\
\text { erlotinib with } \\
\text { gemcitabine plus } \\
\text { platinum followed by } \\
\text { erlotinib) }\end{array}$ & $\mathrm{PFS} / \mathrm{TT} \mathrm{P}^{\mathrm{k}}$ & $226^{\prime}$ & $\begin{array}{l}\text { Median, } 18.3 \text { months }(95 \% \\
\mathrm{Cl}, 16.3 \text { to } 20.8)\end{array}$ & $\begin{array}{l}\text { Median, } 7.6 \text { months }(95 \% \\
\text { Cl, } 7.2 \text { to } 8.3)\end{array}$ & 97 & 43.0 \\
\hline & & $\begin{array}{l}\text { Chemotherapy plus } \\
\text { placebo (intercalated } \\
\text { placebo with } \\
\text { gemcitabine plus } \\
\text { platinum followed by } \\
\text { placebo) }\end{array}$ & & 225 & $\begin{array}{l}\text { Median, } 15.2 \text { months }(95 \% \\
\mathrm{Cl}, 12.7 \text { to } 17.5)\end{array}$ & $\begin{array}{l}\text { Median, } 6 \text { months }(95 \% \\
\qquad \mathrm{Cl}, 5.6 \text { to } 7.1)\end{array}$ & 41 & 18.0 \\
\hline $\begin{array}{l}\text { Statistics and } \\
\text { significance }\end{array}$ & & & & & $\begin{array}{l}\mathrm{HR}, 0.79(95 \% \mathrm{Cl}, 0.64 \text { to } \\
\quad 0.99 ; P=.042)\end{array}$ & $\begin{array}{l}\mathrm{HR}, 0.57(95 \% \mathrm{Cl}, 0.47 \text { to } \\
\quad 0.69 ; P<.001)^{\mathrm{k}}\end{array}$ & & .001 \\
\hline \multirow[t]{2}{*}{ Zukin et al ${ }^{55}$} & & $\begin{array}{l}\text { Carboplatin plus } \\
\text { pemetrexed }\end{array}$ & OS & $103^{m}$ & $\begin{array}{l}\text { Median, } 9.3 \text { months }(95 \% \\
\mathrm{Cl}, 7.2 \text { to } 11.2)\end{array}$ & $\begin{array}{l}\text { Median, } 5.8 \text { months }(95 \% \\
\quad \mathrm{Cl}, 4.7 \text { to } 6.9)\end{array}$ & 19 & 18.4 \\
\hline & & Pemetrexed & & 102 & $\begin{array}{l}\text { Median, } 5.3 \text { months }(95 \% \\
\qquad \mathrm{Cl}, 4.1 \text { to } 6.5)\end{array}$ & $\begin{array}{l}\text { Median, } 2.8 \text { months }(95 \% \\
\text { Cl, } 2.5 \text { to } 3.2)\end{array}$ & 7 & 6.9 \\
\hline $\begin{array}{l}\text { Statistics and } \\
\text { significance }\end{array}$ & & & & & $\begin{array}{l}\mathrm{HR}, 0.62(95 \% \mathrm{Cl}, 0.46 \text { to } \\
\quad 0.83 ; P=.001)\end{array}$ & $\begin{array}{l}\mathrm{HR}, 0.46(95 \% \mathrm{Cl}, 0.35 \text { to } \\
\quad 0.63 ; P<.001)\end{array}$ & $P=$ & $.032^{n}$ \\
\hline \multirow[t]{3}{*}{ Perol et al ${ }^{40}$} & & $\begin{array}{l}\text { Continuation } \\
\text { maintenance with } \\
\text { gemcitabine }\end{array}$ & PFS/TTP & 154 & Median, 12.1 months & Median, 3.8 months & & \\
\hline & & $\begin{array}{l}\text { Switch maintenance } \\
\text { with erlotinib }\end{array}$ & & 155 & Median, 11.4 months & Median, 2.9 months & & \\
\hline & & Observation & & 155 & Median, 10.8 months & Median, 1.9 months & & \\
\hline $\begin{array}{l}\text { Statistics and } \\
\text { significance }\end{array}$ & & & & & $\begin{array}{l}\text { HR } v \text { gemcitabine, } 0.89 \\
\quad(95 \% \mathrm{Cl}, 0.69 \text { to } 1.15 ; \\
\text { log-rank } P=.3867) ; \mathrm{HR} \\
\quad \text { verlotinib, } 0.87(95 \% \\
\mathrm{Cl}, 0.68 \text { to } 1.13 ; \text { log- } \\
\text { rank } P=.3043)\end{array}$ & $\begin{array}{l}\text { HR } v \text { gemcitabine, } 0.56 \\
\quad(95 \% \mathrm{Cl}, 0.44 \text { to } 0.72 ; \\
\text { log-rank } P<.001) ; \mathrm{HR} \\
\quad \text { v erlotinib, } 0.69(95 \% \\
\mathrm{Cl}, 0.54 \text { to } 0.88 ; \text { log- } \\
\text { rank } P=.003 \text { ) }\end{array}$ & & \\
\hline \multirow[t]{2}{*}{$\begin{array}{l}\text { Zhou et al }{ }^{13} \\
\text { Chen et al }{ }^{14}\end{array}$} & OPTIMAL & Erlotinib & PFS/TTP & 82 & Deaths, $16(20 \%)$ of $82^{\circ}$ & $\begin{array}{l}\text { Median, } 13.7 \text { months } \\
\qquad(95 \% \mathrm{Cl}, 10.6 \text { to } 15.3)\end{array}$ & 68 & 83.0 \\
\hline & & $\begin{array}{l}\text { Four cycles gemcitabine } \\
\text { plus carboplatin }\end{array}$ & & 72 & Deaths, $12(17 \%)$ of 72 & $\begin{array}{l}\text { Median, } 4.6 \text { months }(95 \% \\
\text { Cl, } 4.21 \text { to } 5.42)\end{array}$ & 26 & 36.0 \\
\hline $\begin{array}{l}\text { Statistics and } \\
\text { significance }\end{array}$ & & & & & Not yet reached ${ }^{13}$ & $\begin{array}{l}\mathrm{HR}, 0.164(95 \% \mathrm{Cl}, 0.105 \\
\quad \text { to } 0.256 ; P<.001)^{14}\end{array}$ & & .001 \\
\hline \multirow[t]{2}{*}{$\begin{array}{l}\text { Fukuoka et al }{ }^{30} \\
\text { Thongprasert et al }{ }^{60}\end{array}$} & IPASS & $\begin{array}{l}\text { Gefitinib versus } \\
\text { carboplatin plus } \\
\text { paclitaxel }\end{array}$ & & 609 & Median, 18.8 months $^{p}$ & Median, 5.7 months & & $43.0^{61}$ \\
\hline & & $\begin{array}{l}\text { Carboplatin plus } \\
\text { paclitaxel }\end{array}$ & & 608 & Median, 17.4 months & Median, 5.8 months & & 32.2 \\
\hline $\begin{array}{l}\text { Statistics and } \\
\text { significance }\end{array}$ & & & & & $\begin{array}{l}\mathrm{HR}, 0.9(95 \% \mathrm{Cl}, 0.79 \text { to } \\
\quad 1.02 ; P=.109)\end{array}$ & $\begin{array}{l}\mathrm{HR}, 0.74(95 \% \mathrm{Cl}, 0.65 \text { to } \\
\quad 0.85)\end{array}$ & \multicolumn{2}{|c|}{$\begin{array}{l}\text { OR, } 1.59 \\
\quad(95 \% \mathrm{Cl} \\
1.25 \text { to } \\
2.01 ; P< \\
.001)\end{array}$} \\
\hline \multirow[t]{2}{*}{ Sequist et al11 } & Lux & Afatinib & PFS/TTP & 230 & $\begin{array}{l}\text { Median, not reached (16.6 } \\
\text { months) }\end{array}$ & Median, 11.1 months & NR & 56.0 \\
\hline & & $\begin{array}{l}\text { Cisplatin plus } \\
\text { pemetrexed }\end{array}$ & & 115 & $\begin{array}{l}\text { Median, not reached ( } 14.8 \\
\text { months) }\end{array}$ & Median, 6.9 months & NR & 23.0 \\
\hline $\begin{array}{l}\text { Statistics and } \\
\text { significance }\end{array}$ & & & & & $\begin{array}{l}\mathrm{HR}, 1.12(95 \% \mathrm{Cl}, 0.73 \text { to } \\
1.73 ; P=.60 ; 25 \text { th } \\
\text { percentile, } 16.6 \vee 14.8 \\
\text { months) }{ }^{q}\end{array}$ & $\begin{array}{l}\mathrm{HR}, 0.58(95 \% \mathrm{Cl}, 0.43 \text { to } \\
\quad 0.78 ; P=.001)^{r}\end{array}$ & \multicolumn{2}{|c|}{$\begin{array}{l}\text { Other: DCR, } \\
90 \% v \\
81 \% ; \\
\text { median } \\
\text { duration of } \\
\text { response, } \\
11.1 \text { v } 5.5 \\
\text { months; } \\
\text { median } \\
\text { duration of } \\
\text { DC, } 13.6 v \\
8.1 \text { months }\end{array}$} \\
\hline \multicolumn{9}{|c|}{ (continued on following page) } \\
\hline
\end{tabular}


Table 2. First-Line and Maintenance Efficacy (continued)

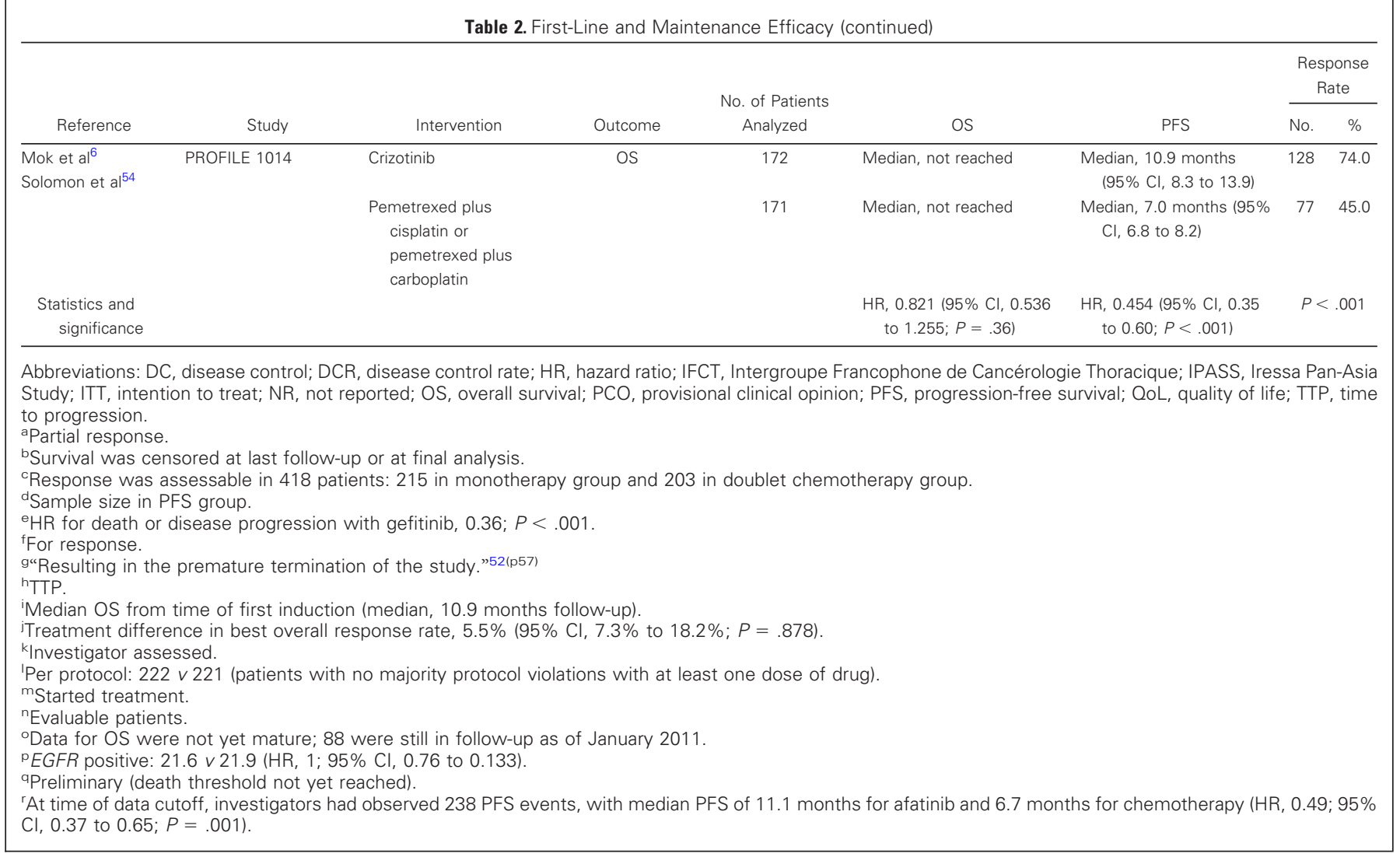

gemcitabine in NSCC. A major gap in current evidence is a lack of direct comparisons of platinum plus pemetrexed with or without bevacizumab. Given the historical lessons learned, the Update Committee does not think it would be fruitful to put valuable resources into a large RCT comparing cisplatin plus pemetrexed with carboplatin plus pemetrexed or with other historical platinum doublets. Therefore, the Update Committee elected to exclude platinum doublets containing gemcitabine for patients with NSCC, whereas carboplatin plus pemetrexed is included as an acceptable regimen for patients with NSCC.

This section will review evidence found in the updated systematic review; as stated, evidence supporting most of the regimens appears in previous versions of the guideline. Many of the current trials included patients with SCC. Specific issues for patients with SCC are discussed under Recommendation A3. The other regimens were in control arms or the standard treatment to which an investigational agent was added.

Regarding cisplatin-based combinations, the trial reported by Scagliotti et $\mathrm{al}^{68}$ was reviewed in the 2009 guideline. ${ }^{1}$ It compared cisplatin plus gemcitabine with cisplatin plus pemetrexed and demonstrated improved OS for patients with adenocarcinoma treated with cisplatin plus pemetrexed (whereas cisplatin plus gemcitabine was superior for patients with SCC). In a trial of cisplatin plus gemcitabine versus gemcitabine, OS and PFS were statistically significantly longer with the combination therapy. QoL was also better; however, the trial had low accrual and was stopped early ${ }^{58}$ (see discussion of PS 2 under Recommendation A2.b). Studies comparing agents in the list of cisplatin-based chemotherapies included one trial that included cisplatin plus docetaxel in the control arm and did not find the interven- tion arm to be superior (intravenous vinorelbine and oral vinorelbine plus cisplatin). ${ }^{69}$ Another trial compared two courses of cisplatin plus gemcitabine plus three courses of gemcitabine (arm one) versus five courses of cisplatin plus gemcitabine (arm two); the study did not demonstrate noninferiority in efficacy, and there was a higher rate of adverse events in arm two. ${ }^{39}$

The only study showing positive results in a comparison between one of the listed cisplatin-based combinations and a new agent was for patients with EGFR-positive NSCLC (see Recommendation A4), in which afatinib was more efficacious than cisplatin plus pemetrexed.

As with the cisplatin regimens, none of the carboplatin regimens listed have shown clear superiority over the others. Nab-paclitaxel was studied in combination with carboplatin. The trial included participants with NSCC and SCC and compared nab-paclitaxel plus carboplatin with solvent-based paclitaxel plus carboplatin and found an improvement in the primary end point of response rate. There was no statistically significant difference in OS. Some adverse events occurred at a lower rate with the intervention. ${ }^{26}$ One trial used two recommended options; carboplatin plus docetaxel was the control arm, and pemetrexed plus carboplatin was the intervention arm. OS, PFS, and response rate were not statistically significantly different. The study did meet its primary end point of OS without grade 3 to 4 toxicity with pemetrexed plus carboplatin. ${ }^{70}$ In a study of pemetrexed plus carboplatin versus gemcitabine plus carboplatin, there was no statistically significant difference in efficacy; however, there were fewer hematologic adverse events with pemetrexed plus carboplatin. ${ }^{18}$ A related study investigated the association of comorbidity with OS, toxicity, or deterioration of health-related QoL (HRQoL). In this instance, the 


\begin{tabular}{|c|c|c|c|c|c|c|c|c|c|}
\hline \multirow[b]{2}{*}{ Reference } & \multirow[b]{2}{*}{ Study } & \multirow{2}{*}{$\begin{array}{l}\text { Treatment } \\
\text { Line }\end{array}$} & \multirow[b]{2}{*}{ Intervention } & \multirow{2}{*}{$\begin{array}{l}\text { Primary } \\
\text { Outcome }\end{array}$} & \multirow{2}{*}{$\begin{array}{l}\text { No. of Patients } \\
\text { Analyzed }\end{array}$} & \multirow[b]{2}{*}{ os } & \multirow[b]{2}{*}{ PFS } & \multicolumn{2}{|c|}{$\begin{array}{c}\text { Response } \\
\text { Rate (CR } \\
+ \text { PR) } \\
\end{array}$} \\
\hline & & & & & & & & No. & $\%$ \\
\hline \multirow[t]{2}{*}{ Garassino et al ${ }^{41}$} & TAILOR & Second & Erlotinib & OS & 109 & $\begin{array}{l}\text { Median, } 5.4 \text { months }(95 \% \mathrm{Cl} \text {, } \\
4.5 \text { to } 6.8 \text { ) }\end{array}$ & $\begin{array}{l}\text { Median, } 2.4 \text { months }(95 \% \mathrm{Cl} \text {, } \\
2.1 \text { to } 2.6)\end{array}$ & $3^{a}$ & 3.0 \\
\hline & & & Docetaxel & & 110 & $\begin{array}{l}\text { Median, } 8.2 \text { months }(95 \% \mathrm{Cl} \text {, } \\
5.8 \text { to } 10.9)\end{array}$ & $\begin{array}{l}\text { Median, } 2.9 \text { months }(95 \% \mathrm{Cl} \text {, } \\
2.4 \text { to } 3.8)\end{array}$ & 15 & 15.5 \\
\hline $\begin{array}{l}\text { Statistics and } \\
\text { significance }\end{array}$ & & & & & & $\begin{array}{l}\mathrm{HR}, 0.78(95 \% \mathrm{Cl}, 0.51 \text { to } \\
\quad 1.05 ; P=.10)\end{array}$ & $\begin{array}{l}\mathrm{HR}, 0.7(95 \% \mathrm{Cl}, 0.55 \text { to } \\
\quad 0.94 ; P=.01)\end{array}$ & $P=$ & .003 \\
\hline \multirow[t]{2}{*}{ Shaw et al ${ }^{56}$} & & Second & Crizotinib & PFS & 173 & $\begin{array}{l}\text { Median, } 20.3 \text { months (95\% } \\
\quad \mathrm{Cl}, 18.1 \text { to not reached) }\end{array}$ & $\begin{array}{l}\text { Median, } 7.7 \text { months }(95 \% \mathrm{Cl} \text {, } \\
\quad 6.0 \text { to } 8.8)\end{array}$ & 112 & 65.0 \\
\hline & & & $\begin{array}{l}\text { Chemotherapy (pemetrexed } \\
\text { or docetaxel) }\end{array}$ & & 174 & $\begin{array}{l}\text { Median, } 22.8 \text { months ( } 95 \% \\
\text { Cl, } 18.6 \text { to not reached) }\end{array}$ & $\begin{array}{l}\text { Median, } 3.0 \text { months }(95 \% \mathrm{Cl} \text {, } \\
2.6 \text { to } 4.3 \text { ) }\end{array}$ & 34 & 20.0 \\
\hline $\begin{array}{l}\text { Statistics and } \\
\text { significance }\end{array}$ & & & & & & $\begin{array}{l}\mathrm{HR}, 1.02(95 \% \mathrm{Cl}, 0.68 \text { to } \\
\quad 1.54 ; P=.54)^{\mathrm{b}}\end{array}$ & $\begin{array}{l}\mathrm{HR}, 0.49(95 \% \mathrm{Cl}, 0.37 \text { to } \\
\quad 0.64 ; P<.001)\end{array}$ & $P<$. & $.001^{\mathrm{c}}$ \\
\hline \multirow[t]{2}{*}{ Miller et al ${ }^{15}$} & Lux-Lung 1 & $\begin{array}{l}\text { Second, third, } \\
\text { and } \\
\text { beyond }\end{array}$ & Afatinib & OS & 390 & $\begin{array}{l}\text { Median, } 10.8 \text { months }(95 \% \\
\quad \mathrm{Cl}, 10.0 \text { to } 12.0 \text { ) }\end{array}$ & $\begin{array}{l}\text { Median, } 3.3 \text { months }(95 \% \mathrm{Cl} \text {, } \\
2.79 \text { to } 4.40)\end{array}$ & $29^{d}$ & 7.0 \\
\hline & & & Placebo & & 195 & $\begin{array}{l}\text { Median, } 12.0 \text { months }(95 \% \\
\quad \mathrm{Cl}, 10.2 \text { to } 14.3 \text { ) }\end{array}$ & $\begin{array}{l}\text { Median, } 1.1 \text { months }(95 \% \mathrm{Cl} \text {, } \\
0.95 \text { to } 1.68)\end{array}$ & $1^{d}$ & 0.5 \\
\hline $\begin{array}{l}\text { Statistics and } \\
\text { significance }\end{array}$ & & & & & & $\begin{array}{l}\mathrm{HR}, 1.08(95 \% \mathrm{Cl}, 0.86 \text { to } \\
\quad 1.35 ; P=.74)\end{array}$ & $\begin{array}{l}\mathrm{HR}, 0.38(95 \% \mathrm{Cl}, 0.31 \text { to } \\
\quad 0.48 ; P<.001)\end{array}$ & $P=. C$ & $0071^{e}$ \\
\hline \multirow[t]{2}{*}{ Quoix et al ${ }^{53}$} & IFCT-0501 & $\begin{array}{l}\text { First and } \\
\text { second }\end{array}$ & Carboplatin plus taxol & $\mathrm{OS}^{\dagger}$ & $\begin{array}{l}226 \text { (144 received } \\
\text { second line) }\end{array}$ & $\begin{array}{l}\text { Median, } 10.3 \text { months }(95 \% \\
\quad \mathrm{Cl}, 8.3 \text { to } 12.6)\end{array}$ & $\begin{array}{l}\text { Median, } 6.0 \text { months }(95 \% \mathrm{Cl} \text {, } \\
5.5 \text { to } 6.8)\end{array}$ & NR & 27.1 \\
\hline & & & Vinorelbine or gemcitabine & & $\begin{array}{l}225 \text { (145 received } \\
\text { second line) }\end{array}$ & $\begin{array}{l}\text { Median, } 6.2 \text { months }(95 \% \mathrm{Cl} \text {, } \\
5.3 \text { to } 7.3)\end{array}$ & $\begin{array}{l}\text { Median, } 2.8 \text { months }(95 \% \mathrm{Cl} \text {, } \\
2.6 \text { to } 3.7)\end{array}$ & NR & 10.2 \\
\hline $\begin{array}{l}\text { Statistics and } \\
\text { significance }\end{array}$ & & & & & & $\begin{array}{l}\mathrm{HR}, 0.64(95 \% \mathrm{Cl}, 0.52 \text { to } \\
\quad 0.78 ; P<.001)\end{array}$ & $P<.001$ & $P<$ & $.001^{9}$ \\
\hline \multirow[t]{2}{*}{ Garon et $\mathrm{al}^{57}$} & REVEL & Second & $\begin{array}{l}\text { Ramucirumab plus } \\
\text { docetaxel }\end{array}$ & OS & 628 & $\begin{array}{l}\text { Median, } 10.5 \text { months (IQR, } \\
5.1 \text { to } 21.2 \text { ) }\end{array}$ & $\begin{array}{l}\text { Median, } 4.5 \text { months (IQR, } \\
2.3 \text { to } 8.3)^{\mathrm{h}}\end{array}$ & & 23.0 \\
\hline & & & Placebo plus docetaxel & & 625 & $\begin{array}{l}\text { Median, } 9.1 \text { months (IQR, } \\
4.2 \text { to } 18 \text { ) }\end{array}$ & $\begin{array}{l}\text { Median, } 3 \text { months (IQR, } 1.4 \\
\text { to } 6.9)^{i}\end{array}$ & 85 & 14.0 \\
\hline $\begin{array}{l}\text { Statistics and } \\
\text { significance }\end{array}$ & & & & & & $\begin{array}{l}\mathrm{HR}, 0.86(95 \% \mathrm{Cl}, 0.75 \text { to } \\
\quad 0.98 ; P=.023)\end{array}$ & $\begin{array}{l}\mathrm{HR}, 0.76(95 \% \mathrm{Cl}, 0.68 \text { to } \\
\quad 0.86 ; P<.001)\end{array}$ & $P<$ & .001 \\
\hline \multicolumn{10}{|c|}{$\begin{array}{l}\text { Abbreviations: CR, complete response; HR, hazard ratio; IFCT, Intergroupe Francophone de Cancérologie Thor } \\
\text { OS, overall survival; PFS, progression-free survival; PR, partial response. } \\
\text { aDisease control rate. } \\
\text { bInterim analysis. } \\
\text { 'Intention to treat. } \\
\text { dPR. } \\
\text { e'Confirmation of response rate was reported separately by independent review and investigator assessment. } \\
{ }^{\text {f }} \text { Survival was censored at last follow-up or at final analysis. } \\
\text { gResponse was assessable in } 418 \text { patients: } 215 \text { in monotherapy group and } 203 \text { in doublet group. } \\
{ }^{\text {h } C e n s o r i n g, ~} 11.1 \% \text {. } \\
{ }^{i} \text { Censoring, } 6.7 \% \text {. }\end{array}$} \\
\hline
\end{tabular}

multiple chronic conditions (MCCs) burden was assessed from hospital medical records using the Cumulative Illness Rating Scale for Geriatrics. Patients with severe comorbidity had survival similar to that of other patients $(6.9 v 8.1$ months; $P=.34)$ and a similar frequency of neutropenia $(48 \% v 42 \% ; P=.16)$ but experienced more neutropenic fevers $(12 \% v 5 \% ; P=.012)$ and deaths resulting from neutropenic infections ( $3 \% v 0 \% ; P=.027)$. They also experienced more thrombocytopenia $(46 \% v 36 \% ; P=.03)$. Patients with severe comorbidity reported poorer HRQoL but not significantly greater deterioration of HRQoL. ${ }^{19}$ In one trial of four cycles of carboplatin plus paclitaxel versus five cycles of vinorelbine or gemcitabine, OS and PFS were statistically significantly longer with carboplatin plus paclitaxel, and adverse events occurred at a higher frequency ${ }^{53}$ (see Recommendation A8 for more on this trial).

Carboplatin plus paclitaxel (ie, taxane plus carboplatin control) was used in both arms of a cetuximab trial that found no statistically significant difference in PFS; it lacked the power to determine an OS difference. ${ }^{71}$ In two trials of gefitinib, ${ }^{20,30,61}$ carboplatin plus paclitaxel constituted the control arm. In the study by Maemondo et $\mathrm{al}^{20}{ }^{20}$ this regimen resulted in poorer outcomes in PFS and TTP and no statistically significant differences in OS with chemotherapy; adverse events occurred at a higher frequency with carboplatin plus paclitaxel. Similar results were published from the IPASS (Iressa Pan-Asia Study) trial. ${ }^{30,61}$ Carboplatin plus paclitaxel was administered to the control arm in a trial of carboplatin plus oral S-1, a regimen used in Japan but not in the United States. The results of this trial showed noninferiority in OS with S-1. ${ }^{72}$ Finally, no new trials included the combination of carboplatin plus irinotecan or carboplatin plus vinorelbine.

There are no FDA-approved nonplatinum regimens. Most of the evidence for nonplatinum combinations was provided in past versions of this guideline. Nonplatinum regimens studied include docetaxel plus vinorelbine, docetaxel plus gemcitabine, gemcitabine plus vinorelbine, paclitaxel plus gemcitabine, and paclitaxel plus vinorelbine. 


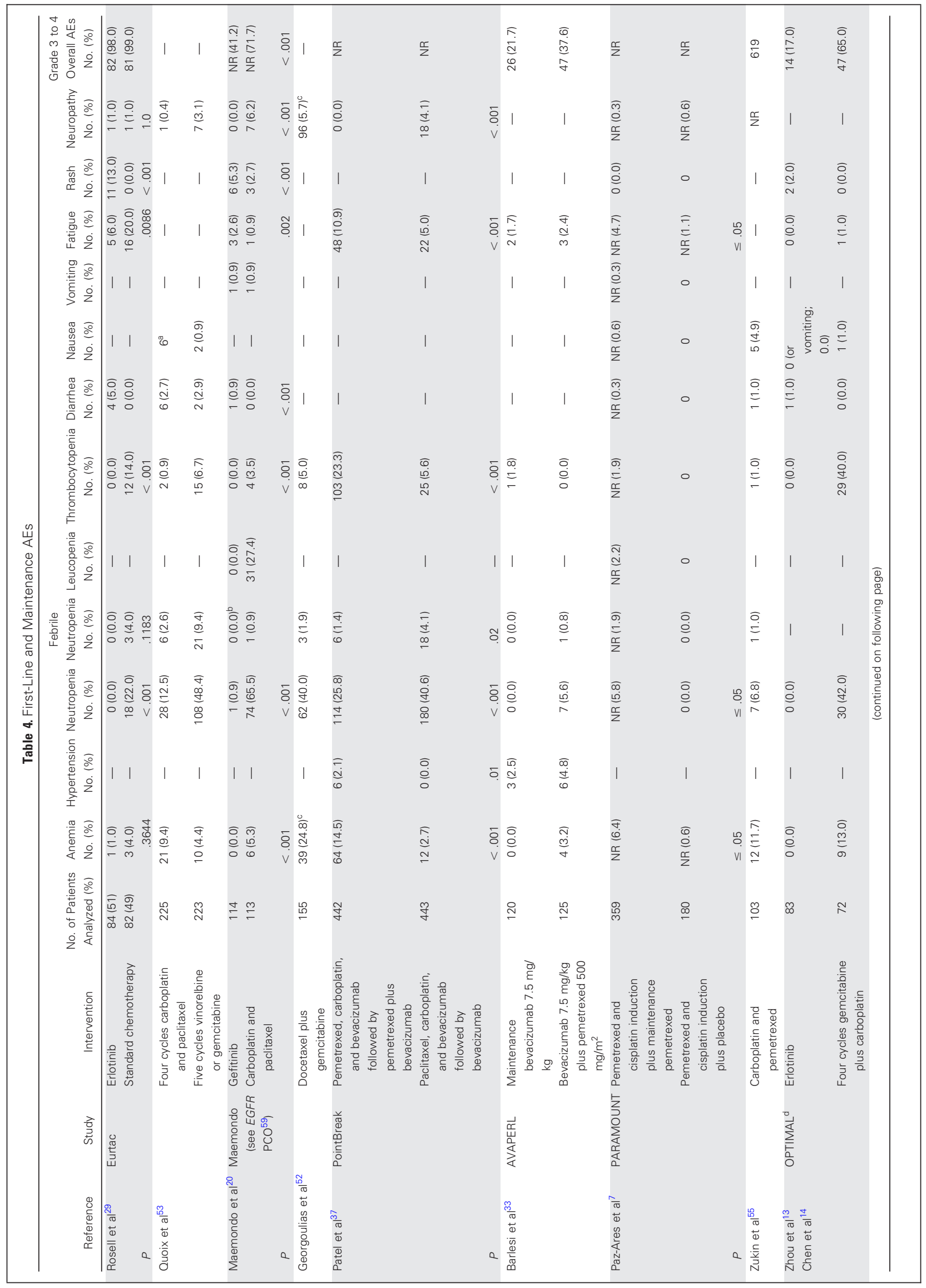


Chemotherapy for Stage IV NSCLC

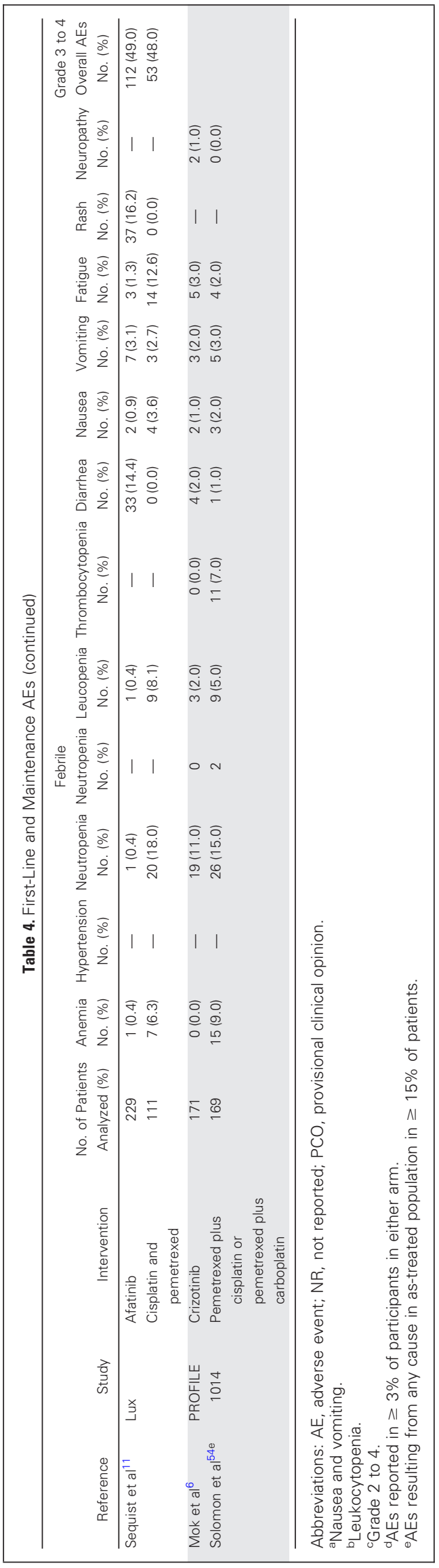


Masters et al

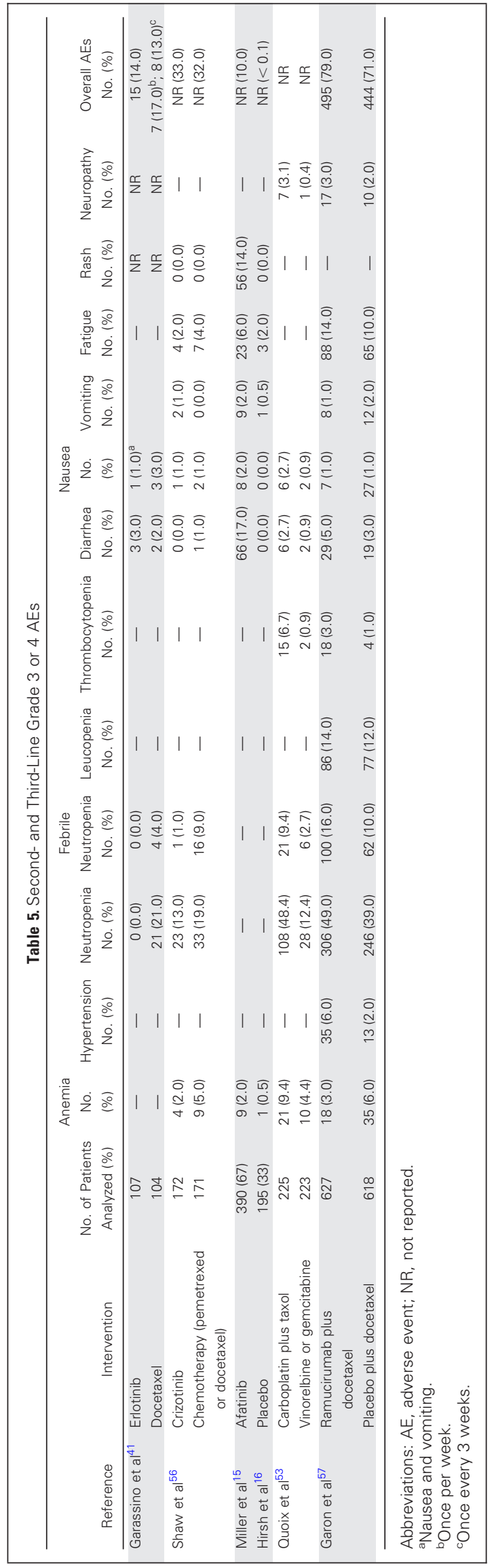


In the updated systematic review, in the three-arm study by Treat et $a{ }^{73}$ although efficacy did not differ between the two platinumcontaining arms and the paclitaxel plus gemcitabine arm, there were fewer adverse effects (eg, neuropathy) without the platinum agent. In a trial comparing docetaxel plus gemcitabine with docetaxel alone, the OS results showed a statistically significant difference of 1.1 months in favor of the doublet; the study was closed prematurely. ${ }^{52}$ Another trial, in which vinorelbine plus gemcitabine followed by docetaxel was compared with carboplatin plus paclitaxel, found that OS and PFS were not statistically significantly different for efficacy, although the response rate was higher with carboplatin plus paclitaxel; each regimen had different toxicity rates that were higher than the other. ${ }^{74}$ One trial compared two nonplatinum regimens (paclitaxel plus gemcitabine $v$ paclitaxel plus vinorelbine); paclitaxel plus vinorelbine did not improve efficacy and increased toxicity. ${ }^{75}$

Clinical interpretation. Multiple trials have evaluated chemotherapy treatment options for stage IV NSCLC. A variety of agents in combination with cisplatin or carboplatin can be recommended in the first-line treatment of NSCLC. There were no compelling data regarding any single regimen for this population; therefore, clinical judgment should guide the choice of therapy among regimens. The choice between regimens may be based on potential toxicities.

\section{CLINICAL QUESTION A2.a}

What is the most effective first-line therapy for patients with stage IV NSCLC with negative or unknown EGFR/ALK status, NSCC, and no contraindications to bevacizumab?

\section{Recommendation A2.a.1}

For patients receiving carboplatin plus paclitaxel, the Update Committee recommends the addition of bevacizumab $15 \mathrm{mg} / \mathrm{kg}$ once every 3 weeks, except for patients with SCC histologic type, clinically significant hemoptysis, inadequate organ function, Eastern Cooperative Oncology Group PS $>1$, clinically significant cardiovascular disease, or medically uncontrolled hypertension. Bevacizumab may be continued, as tolerated, until disease progression (no change since 2011; type: evidence based, benefits outweigh harms; evidence quality: intermediate; strength of recommendation: moderate).

\section{Recommendation A2.a.2}

There is insufficient evidence (for or against) to recommend pemetrexed in combination with bevacizumab plus carboplatin for patients who do not have contraindications to bevacizumab.

Literature review update and analysis. As of the 2011 guideline update, evidence of improvements in OS and PFS with the addition of bevacizumab to carboplatin plus paclitaxel supported the affirmative recommendation for this combination for patients meeting certain criteria, especially the criterion of having NSCC. In the present updated systematic review, four RCTs were identified that included bevacizumab $33,35,37,76$ - three in the maintenance setting. A fourth trial in the maintenance setting investigated the addition of pemetrexed to bevacizumab. It compared pemetrexed plus carboplatin and bevacizumab followed by maintenance pemetrexed and bevacizumab (arm one) versus paclitaxel plus carboplatin and bevacizumab followed by maintenance bevacizumab (arm two). ${ }^{37}$ PFS, but not OS, was improved using bevacizumab plus pemetrexed. Some adverse events occurred at a higher frequency in one arm and some in the other (eg, neutropenia and febrile neutropenia were more frequent in arm two; thrombocytopenia and anemia were more frequent in arm one). A second trial ${ }^{33}$ compared maintenance pemetrexed plus bevacizumab with bevacizumab alone (after first-line induction with bevacizumab, cisplatin, and pemetrexed). The study met its primary end point of statistically significantly longer PFS with bevacizumab plus pemetrexed ( $7.4 v 3.7$ months; hazard ratio [HR], 0.48 ; $95 \% \mathrm{CI}, 0.35$ to $0.66 ; P<.001)$. At the time of study publication, OS had not yet been reached. The adverse events were not statistically significantly more frequent in the intervention arm. ${ }^{33}$ One trial of two different doses of bevacizumab in combination with cisplatin plus gemcitabine versus a placebo provided updated OS results (earlier results were reviewed in 2009 guideline). The results were not statistically significantly different and therefore do not provide support for changing the current recommendation. ${ }^{76}$

One trial that compared bevacizumab plus erlotinib versus bevacizumab plus placebo resulted in a 1.1-month longer PFS - the primary end point of the study-but there was no increase in OS, and adverse events were more frequent or of higher grade with the intervention. ${ }^{35}$ Participants with SCC were included in the negative erlotinib trial and were not eligible for the other trials.

Clinical interpretation. None of the trials found provide support for adding bevacizumab to chemotherapy regimens other than carboplatin plus paclitaxel. The Update Committee believes that carboplatin plus paclitaxel is the only regimen for which the data support the addition of bevacizumab. The data regarding adding bevacizumab to carboplatin plus pemetrexed are not yet mature; therefore, there are insufficient data on which to base a recommendation.

As discussed in the 2009 guideline, ${ }^{1}$ there were unplanned retrospective analyses of the pivotal trial and additional observational data on patients age $\geq 65$ or 70 years, suggesting caution in this population. ${ }^{77,78 ~ " T h e r e ~ i s ~ s p e c i a l ~ c o n c e r n ~ f o r ~ t o x i c i t y ~ i n ~ t h e ~ e l d e r l y ~ p o p u l a-~}$ tion, based on a subgroup analysis of the major phase III trial, which showed increased toxicity and no obvious improvement in OS in the elderly subgroup."1(p6257)

\section{CLINICAL QUESTION A2.b}

What is the most effective first-line therapy for patients with stage IV NSCLC with PS 2, NSCC, and negative or unknown EGFRsensitizing mutation and $A L K$ gene rearrangement status?

\section{Recommendation A2.b}

In the context of shared decision making, combination therapy, single-agent chemotherapy, or palliative therapy alone may be used for patients in this population with PS 2 (chemotherapy: type: evidence based, benefits outweigh harms; evidence quality: intermediate; strength of recommendation: weak; palliative care: type: evidence based, benefits outweigh harms; evidence quality: intermediate; strength of recommendation: strong).

Literature review update and analysis. The updated systematic review identified two small trials specifically comparing single agent versus combination chemotherapy in patients with PS 2. The first trial, ${ }^{55}$ which included 205 participants, compared carboplatin plus pemetrexed with pemetrexed alone. In the results, OS and PFS were statistically significantly longer with the combination. Adverse events were slightly more frequent with the combination, but the results were not statistically significant. ${ }^{55}$ One trial with 56 participants compared cisplatin plus gemcitabine with gemcitabine and found that OS and PFS were statistically significantly longer with the combination and 
QoL was also higher; however, the study was stopped early and had few participants. ${ }^{58}$ Twenty $^{6,13,18,27,28,34,36,38,39,44,52,53,55,58,70,79-82}$ of 44 new first-line studies in the updated systematic review included patients with PS 2. The Cochrane systematic review on chemotherapy and supportive care, updated in 2012, continued to show that chemotherapy and best supportive care versus supportive care alone benefit patients, including those who have PS $2 .^{83}$

Clinical interpretation. Combination treatment can improve outcomes for patients with negative or unknown EGFR/ALK status with NSCC histology and PS 0 to 2 who may also receive treatment with either combination or single-agent chemotherapy or palliative care concurrently or alone. It is difficult for clinicians to know which patients have a higher PS score because of tumor burden alone, who will improve with response to treatment, and who can be supported for 6 weeks until a response is evident. There are not yet sufficient objective tools available to clinicians to determine which patients would benefit and tolerate combined therapy in comparison with single-agent chemotherapy. Patients with PS 2 make up fewer than half of patients enrolled onto clinical trials. ${ }^{84}$ Trials limited to patients with PS 2 have typically not reported the cause for designation of PS 2 (ie, cancer-related symptoms secondary to large tumor burden $v$ poor PS designation because of MCC). The data informing chemotherapy decisions for patients with PS 2 are insufficient to make a strong recommendation favoring combination chemotherapy. Patients and clinicians should discuss the risks and benefits of combination chemotherapy. Some patients may choose single-agent chemotherapy if their perception of risk outweighs perceived benefits of combination therapy.

\section{CLINICAL QUESTION A3}

What is the most effective first-line therapy for patients with stage IV NSCLC with SCC, negative or unknown EGFR-sensitizing mutation and $A L K$ gene rearrangement status, and PS 0 to 1 or possibly PS 2?

\section{Recommendation A3}

Patients with the characteristics listed in Clinical Question A3 and with SCC histology should be offered the following options:

- Cisplatin-based combinations (type: evidence based, benefits outweigh harms; evidence quality: high; strength of recommendation: strong)

- Cisplatin plus docetaxel (FDA-approved combination; http://www.cancer.gov)

- Cisplatin plus gemcitabine (FDA-approved combination; http://www.cancer.gov)

- $\quad$ Cisplatin plus paclitaxel (FDA-approved combination; http://www.cancer.gov)

- Cisplatin plus vinorelbine (FDA-approved combination; http://www.cancer.gov)

- Carboplatin-based combinations (type: evidence based, benefits outweigh harms; evidence quality: high; strength of recommendation: strong)

- Carboplatin plus gemcitabine

- Carboplatin plus paclitaxel (FDA-approved combination; http://www.cancer.gov)

- Carboplatin plus nab-paclitaxel (FDA-approved combination; http://www.cancer.gov)

\section{- Carboplatin plus docetaxel}

- Nonplatinum doublets (type: evidence based, benefits outweigh harms; evidence quality: low; strength of recommendation: weak)

Literature review update and analysis. All regimens discussed in Recommendation A2, with the exception of pemetrexed-containing regimens and bevacizumab, are also recommended for patients with SCC. Non-FDA-approved regimens include the following nonplatinum combinations: docetaxel plus vinorelbine, docetaxel plus gemcitabine, gemcitabine plus vinorelbine, paclitaxel plus gemcitabine, and paclitaxel plus vinorelbine.

Clinical interpretation. Most of the trials evaluating chemotherapy options in the first-line setting did not report any differential efficacy in patients with SCC. A retrospective review of trials of antimicrotubule plus platinum chemotherapy conducted by SWOG reported no differential effect of histology on treatment. ${ }^{85}$ The trial by Scagliotti et $\mathrm{al}^{68}$ comparing cisplatin plus gemcitabine with cisplatin plus pemetrexed demonstrated improved OS for patients with SCC treated with cisplatin plus gemcitabine. The results of this trial suggest that a platinum agent plus pemetrexed should not be administered in patients with SCC, and in fact, licensing in many health care jurisdictions limits the use of pemetrexed for patients with nonsquamous histology. Platinum-based combinations are generally considered to be more effective than non-platinum-based doublets. There is no evidence of any differential effect of histology on treatment for nonplatinum combinations.

As with other regimens discussed in this guideline, choice of therapy should take into account both the treatment schedule and toxicity profile of the specific chemotherapy drugs. Toxicity concerns, particularly major bleeding complications, are relative contraindications to the use of bevacizumab in patients with SCC.

\section{CLINICAL QUESTION A3.a}

What is the most effective first-line therapy for patients with stage IV NSCLC with negative or unknown EGFR/ALK status, SCC, and PS 2?

\section{Recommendation A3.a}

In the context of shared decision making, combination chemotherapy, single-agent chemotherapy, or palliative therapy alone may be used for patients with the characteristics described in Clinical Question A3.a. (Chemotherapy: type: evidence based, benefits outweigh harms; evidence quality: intermediate; strength of recommendation: weak. Palliative care: type: evidence based, benefits outweigh harms; evidence quality: intermediate; strength of recommendation: strong.)

Literature review and analysis. See Recommendation A2.b.

Clinical interpretation. Patients with negative or unknown EGFR/ALK status with SCC histology and PS 2 may benefit from treatment with either combination or single-agent chemotherapy. This recommendation is based on clinical trial evidence with intermediate overall evidence quality. The benefits are greater than the harms, although the strength of the recommendation is weak, because too few patients were studied in the RCTs, and there is no effective tool to determine which patients will tolerate doublet therapy and experience an improvement in PS with a reduction of symptoms and which patients will experience an acceleration of their decline with treatment. These patients should also be offered concurrent palliative care or palliative care alone as an alternative to chemotherapy. 


\section{CLINICAL QUESTION A4}

What is the most effective first-line therapy for patients with stage IV NSCLC with an EGFR-sensitizing mutation and PS 0 to 1 or possibly PS 2?

\section{Recommendation A4}

If patients have stage IV NSCLC and a sensitizing EGFR mutation, first-line afatinib (type: evidence based, benefits outweigh harms; evidence quality: high; strength of recommendation: strong), erlotinib (type: evidence based, benefits outweigh harms; evidence quality: high; strength of recommendation: strong), or gefitinib (type: evidence based, benefits outweigh harms; evidence quality: high; strength of recommendation: strong) is recommended.

Literature review update and analysis. Since the publication of the ASCO 2009 guideline and the ASCO EGFR provisional clinical opinion, ${ }^{59}$ results from seven trials of first-line EGFR TKIs for patients with EGFR mutations have been published. ${ }^{11,13,29,31,34,36,40}$ Three studies specifically required evidence that all participants had EGFR mutations. ${ }^{11,13,29}$ Two trials, in which PFS was the primary end point, compared first-line erlotinib with chemotherapy. In one small study, there was a PFS benefit with erlotinib ( $9.7 v 5.2$ months; HR, $0.37 ; 95 \%$ CI, 0.25 to $0.54 ; P<.001$ ); OS had not been reached by the time of publication. ${ }^{29}$ There was incidence of higher fatigue, rash, and diarrhea with erlotinib compared with chemotherapy. In the second small study, which was a publication of an abstract in the provisional clinical opinion, there was a longer PFS (erlotinib: 13.7 months; 95\% CI, 10.6 to 15.3 ; control: 4.6 months; $95 \% \mathrm{CI}, 4.2$ to 5.4 ; HR, 0.164 ; $95 \% \mathrm{CI}$, 0.11 to $0.26 ; P<.001)$; OS had not yet been reached. ${ }^{13,14}$ Rash incidence was higher with erlotinib, although only small numbers of participants experienced grade 3 to 4 rash. ${ }^{13}$ In both studies of selected patients, incidence of neutropenia, thrombocytopenia, and anemia was higher with chemotherapy. ${ }^{13,29}$

Afatinib is a second-generation, irreversible ErbB family inhibitor. One study, with PFS as primary outcome, compared first-line afatinib with cisplatin plus pemetrexed. The results showed improvement with afatinib ( $11.1 v 6.9$ months; HR, 0.58 ; $95 \%$ CI, 0.43 to 0.78 ; $P=.001)$. Survival was not significantly longer (16.6 $v 14.8$ months). Afatinib was approved by the FDA on the basis of this study ${ }^{86}$ for patients with L858R mutations and/or exon 19 deletions. A prespecified analysis of patients with these common mutations showed a PFS of 13.6 versus 6.9 months for chemotherapy (HR, $0.47 ; 95 \%$ CI, 0.34 to $0.65 ; P=.001){ }^{11}$

Briefly, the ASCO provisional clinical opinion ${ }^{59}$ discussed results of the IPASS trial comparing gefitinib with carboplatin plus paclitaxel. A statistically significant PFS was found for all patients in the trial treated with gefitinib, including those whose tumors were EGFR mutation positive. ${ }^{61}$ The updated systematic review included final OS results, which were not statistically significantly different (overall: 18.8 $v 17.4$ months; EGFR positive: $21.6 v 21.9$ months). ${ }^{30}$ The report also noted that "although these values [PFS] were reported in the original publications, a single $\mathrm{HR}$ is not readily interpretable because the survival curves cross, suggesting a violation of the proportional hazards assumption." ${ }^{59(\mathrm{p} 4)}$ Updated results of another trial discussed in the EGFR provisional clinical opinion that compared gefitinib versus carboplatin plus paclitaxel continued to show statistically significant outcomes for PFS but not OS and will not be further discussed here. ${ }^{20,21}$ Two studies of gefitinib as switch maintenance found PFS but not OS benefits. ${ }^{34,36}$
Clinical interpretation. There is overwhelming and consistent evidence now from multiple trials that gefitinib, erlotinib, or afatinib have greater activity than platinum-based chemotherapy in the first-line treatment of patients with advanced NSCLC with activating EGFR mutations. There have been significant improvements in response rate and TTP favoring gefitinib, erlotinib, or afatinib. These agents have more favorable toxicity profiles than platinum-based chemotherapy and have demonstrated improvements in QoL. Despite the absence of clear improvements in OS, gefitinib, erlotinib, or afatinib is a preferred treatment based on large improvements in other outcomes.

The choice of which EGFR TKI to recommend to patients should be based on the availability and toxicity of the individual agent. There are no results from direct comparative trials of different EGFR TKIs. Therefore, it is not possible to make a recommendation favoring one EGFR TKI over another. RCTs are ongoing, comparing gefitinib with afatinib, as well as gefitinib with dacomitinib, another pan-HER inhibitor. The results of these trials may help refine this recommendation in the future.

\section{CLINICAL QUESTION A5}

What is the most effective first-line therapy for patients with stage IV NSCLC with ALK gene rearrangement and PS 0 to 1 or possibly PS 2 ?

\section{Recommendation A5}

If patients have stage IV NSCLC and ALK rearrangements, first-line crizotinib is recommended (type: evidence based, benefits outweigh harms; evidence quality: high; strength of recommendation: strong).

Literature review update and analysis. FDA approval of crizotinib is based on data from the second-line setting comparing crizotinib with chemotherapy. ${ }^{56}$ The chemotherapy used was pemetrexed, unless a patient had received prior pemetrexed or had SCC, in which case the patient received docetaxel. An interim analysis found a median OS of 20.3 months ( $95 \%$ CI, 18.1 to not reached) for crizotinib versus 22.8 months (95\% CI, 18.6 to not reached) for chemotherapy (HR, 1.02; $95 \% \mathrm{CI}, 0.68$ to $1.54 ; P=.54)$. The PFS results were 7.7 months ( $95 \%$ CI, 6.0 to 8.8 ) with crizotinib compared with 3.0 months (95\% CI, 2.6 to 4.3 ) with chemotherapy (HR, $0.49 ; 95 \% \mathrm{CI}, 0.37$ to $0.64 ; P<.001$ ). Incidence of grade 3 to 4 febrile neutropenia was lower with crizotinib, but grade 3 to 4 elevated liver aminotransferase levels were higher with crizotinib $(16 \% v 2 \%)$. Vision disorders of any grade were experienced by $60 \%$ versus $9 \%$ of patients (but there were no incidences of grade 3 to 4 disorders in either arm). The overall grade 3 to 4 adverse event rate was $33 \%$ versus $32 \%$ for the crizotinib versus control arm, respectively, and treatment-related serious adverse events were experienced by $12 \%$ versus $14 \%$ of patients.

Since the publication of the second-line trial, ${ }^{56}$ one phase III trial (PROFILE 1014; ClinicalTrials.gov identifier NCT01154140) ${ }^{54}$ comparing crizotinib with standard first-line chemotherapy (either platinum drug plus pemetrexed) for patients with known $A L K$ rearrangements was presented and published (after data cutoff for this guideline). This trial of 343 participants reached its primary end point of higher PFS with crizotinib ( $10.9 v 7$ months; HR, $0.454 ; 95 \%$ CI, 0.346 to $0.596 ; P$ $<.001)$. The response rate was also higher at $P<.001$. Survival was not significantly different $(P=.36)$. Adverse events that were more frequent with crizotinib included diarrhea, elevated transaminases, 
and vision disorders. Some hematologic adverse events were more frequent with chemotherapy, as was vomiting. ${ }^{6,54}$

Clinical interpretation. ALK gene rearrangement in NSCLC is a perfect model for the rapidly evolving field of molecular profiling in oncology. $A L K$ gene rearrangements are identified in a small proportion of newly diagnosed patients with NSCLC (approximately $5 \%)^{77,87-89}$ However, these uncommon tumors are important to identify, because they are treatable with FDA-approved oral agents (crizotinib and ceritinib). These agents offer equal or superior efficacy and toxicity profiles compared with standard cytotoxic chemotherapy. The availability of these agents and companion diagnostics now makes testing for these mutations a new standard of care. ${ }^{3}$

The toxicity of these agents includes a low risk of any grade 3 or 4 toxicity. This is generally comparable to standard cytotoxic chemotherapy, with the exception of liver toxicity. Grade 3 to 4 elevation of liver transaminase is much more frequent with these agents than traditionally seen with cytotoxic chemotherapy and needs careful monitoring. In rare cases, crizotinib has been associated with severe interstitial pneumonitis that has been fatal. Visual disturbance is a frequent abnormality noted with crizotinib, but this is always mild (grade 1 or 2) and does not require drug termination. Crizotinib is preferred for patients with PS 0 to 2 and ALK gene rearrangement on the basis of its impressive efficacy in early studies. There has not yet been a published peer-reviewed report of phase III results.

\section{CLINICAL QUESTION A6}

What is the most effective first-line therapy for patients with stage IV NSCLC with ROS1 rearrangement, no ALK gene rearrangement, negative or unknown EGFR-sensitizing mutation status, and PS 0 to 1 or possibly PS 2 ?

\section{Recommendation A6}

If patients have stage IV NSCLC with ROS1 rearrangement, single-agent crizotinib is recommended, because it has shown some results indicating improved response rate and duration of response (type: informal consensus, benefits outweigh harms; evidence quality: low; strength of recommendation: weak).

Clinical interpretation. Because no data were found in the systematic review to inform this clinical question, the Update Committee chose to make an informal consensus recommendation. The Update Committee relied on clinical experience, training, and judgment to formulate this recommendation, given that there were no conclusive data regarding this question. A study ${ }^{78}$ was published after the close of the date parameters for the systematic review that included 50 patients from a second-line crizotinib trial who had ROS1 rearrangements. The objective response rate was 72\% (95\% CI, 58 to 84), and there were three complete responses and 33 partial responses. Median duration of response was 17.6 months ( $95 \% \mathrm{CI}, 14.5$ to not reached). Median PFS was 19.2 months (95\% CI, 14.4 to not reached). The authors state that "the safety profile of crizotinib was similar to that seen in patients with ALK-rearranged NSCLC." ${ }^{\text {(p1) }}$ Although these results are from an early trial, they are impressive.

\section{CLINICAL QUESTION A7}

What is the most effective first-line therapy for patients with stage IV NSCLC with negative or unknown EGFR/ALK status and large-cell neuroendocrine carcinoma?

\section{Recommendation A7}

Patients with large-cell neuroendocrine carcinoma may receive the same treatment as other patients with NSCC or treatment with etoposide in platinum combinations (type: informal consensus, benefits outweigh harms; evidence quality: low; strength of recommendation: weak).

Clinical interpretation. Given that there were no data informing this question, the Update Committee relied on clinical experience, training, and judgment to formulate this recommendation. As a result of the clinical similarity of large-cell neuroendocrine carcinoma to NSCC, the Update Committee believes a platinum plus etoposide combination may provide optimal efficacy to patients whose tumors have this histology. ${ }^{90}$

\section{CLINICAL QUESTION A8}

What is the best chemotherapy for treatment of the elderly with stage IV NSCLC?

\section{Recommendation A8}

Decisions on the selection of chemotherapy should not be made or altered based on age alone (type: evidence based, benefits outweigh harms; evidence quality: high; strength of recommendation: strong).

Literature review update and analysis. This recommendation is based on evidence presented in the 2009 guideline update. ${ }^{1}$ No evidence was found to contradict this recommendation in the current systematic review. The studies found in the current systematic review included the French multicenter randomized phase III trial Intergroupe Francophone de Cancérologie Thoracique (IFCT) $0501,{ }^{53}$ the largest prospective trial to successfully compare a platinum-based combination regimen with single-agent chemotherapy in an elderly population. It compared four cycles of carboplatin plus paclitaxel versus monotherapy; OS favored the doublet for an elderly population. Median OS was superior for doublet chemotherapy versus monotherapy ( $10.3 v 6.2$ months; HR, $0.64 ; P<.001)$. This benefit was retained with doublet therapy in the subgroup with PS 2 and in those age $>80$ years, which each constituted approximately one fourth of the study population. However, the OS of patients with PS 2 was inferior to that of patients with PS 0 to 1 in multivariable analysis. Also, the study exclusions included "patients with comorbidities that impaired administration of chemotherapy or who had respiratory

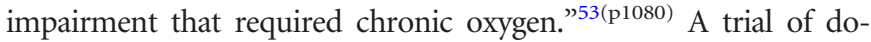
cetaxel versus vinorelbine showed no significant differences in efficacy and closed early as a result of low accrual. ${ }^{79}$ A QoL study of carboplatin plus gemcitabine versus carboplatin plus paclitaxel found no statistically significant difference. ${ }^{44}$

Clinical interpretation. ASCO recognizes the wide variability in patient tolerance to various chemotherapy and targeted agents for lung cancer. However, multiple trials did not identify age as a pretreatment risk factor for either tolerance or response to treatment with cytotoxic therapy. ${ }^{1}$ The 2009 full guideline ${ }^{1}$ and the 2011 update $^{2}$ of the guideline for chemotherapy for stage IV NSCLC strongly support treatment based on functional status and comorbidity. There is no change from the previous version of the guideline.

Current trials of targeted agents such as EGFR inhibitors have not addressed the age variable explicitly. These trials required that participants be age $>18$ years to participate but did not exclude elderly patients on the basis of age. There is no evidence as yet that these agents are more harmful or less active in elderly patients. Consequently, 
elderly patients should be treated on the basis of functional status and stage as per previous guidelines. ${ }^{2}$ Because both PS 2 and elderly populations are heterogeneous, and diminished PS can be a consequence of cancer-related symptoms or MCC, chemotherapy decisions in these subgroups must be individualized, with patient and caregiver input, to optimize outcomes fully with regard to efficacy and treatment-related toxicities. There is no change from the previous guideline, and the Update Committee emphasizes that age alone should not be a criterion for deciding therapy for elderly patients.

\section{CLINICAL QUESTION A9}

What is the optimal treatment for patients with stable disease or response after four cycles of cytotoxic chemotherapy?

\section{Recommendation A9}

In patients with stage IV NSCLC, first-line cytotoxic chemotherapy should be stopped at disease progression or after four cycles in patients whose disease is stable but not responding to treatment; two-drug cytotoxic combinations should be administered for no more than six cycles. For patients with stable disease or response after four cycles of a first-line pemetrexed-containing regimen, continuation maintenance treatment with pemetrexed is recommended. For patients with stable disease or response after four cycles of a regimen that did not include a pemetrexed-containing combination, alternative single-agent chemotherapy, such as pemetrexed in patients with nonsquamous histology, docetaxel in unselected patients, or erlotinib in unselected patients, or a break from cytotoxic chemotherapy with initiation of second-line chemotherapy at disease progression may be recommended (addition of pemetrexed: type: evidence based, benefits outweigh harms; evidence quality: intermediate; strength of recommendation: moderate).

Literature review update and analysis. Because the ASCO 2011 update focused on the question of switch maintenance, ${ }^{2}$ this recommendation has been updated to add continuation maintenance, specifically with pemetrexed, for those with stable disease or response after first-line pemetrexed. This is based on the PARAMOUNT trial (Phase 3, Double-Blind, Placebo-Controlled Study of Maintenance Pemetrexed Plus Best Supportive Care Versus Best Supportive Care Immediately Following Induction Treatment With Pemetrexed + Cisplatin for Advanced Non-Squamous Non-Small Cell Lung Cancer; ClinicalTrials.gov identifier NCT00789373) of 539 participants receiving pemetrexed plus cisplatin induction plus maintenance pemetrexed versus pemetrexed plus cisplatin induction plus placebo. The PFS result was improved (4.4 months; 95\% CI, 4.1 to 5.7) with pemetrexed maintenance versus the control (2.8 months; 95\% CI, 2.6 to 3.0). OS was 2.9 months longer ( $13.9 v 11$ months; unadjusted HR $P=$ .019). Neutropenia, anemia, and fatigue occurred more frequently in the intervention arm. ${ }^{7,8}$ The results of the PointBreak trial of maintenance pemetrexed and bevacizumab after pemetrexed, carboplatin, and bevacizumab are reviewed under Recommendation A2.a.1. In brief, this intervention was superior in PFS but not OS to maintenance bevacizumab after carboplatin, paclitaxel, and bevacizumab. The authors refer readers to reports by Murray et $\mathrm{al}^{91}$ and Paz-Ares et $\mathrm{al}^{92}$ for further discussion.

Other studies found in the updated systematic review did not result in evidence supporting other changes in the recommendation. These studies investigated thalidomide, ${ }^{38}$ bevacizumab plus erlo- tinib, ${ }^{35}$ gemcitabine, ${ }^{39}$ bevacizumab plus pemetrexed, ${ }^{33,37}$ bevacizumab alone, ${ }^{37}$ and gefitinib. ${ }^{34,36}$

Clinical interpretation. Maintenance therapy is used to prolong a clinically favorable state after completion of a predefined number of induction chemotherapy cycles. Continuation maintenance therapy involves uninterrupted administration of a component of the initial chemotherapy regimen, most commonly the nonplatinum cytotoxic drug or a molecular targeted agent. Sequential or switch maintenance involves the introduction of a new and potentially non-cross-resistant agent on completion of first-line chemotherapy. To date, switch maintenance therapy strategies with pemetrexed and erlotinib have demonstrated improved OS, resulting in FDA approval for this indication. Recently, continuation maintenance with pemetrexed was found to prolong OS as well. Several factors influence the decision to implement maintenance therapy, including tumor histology, clinical and radiologic response to induction, tumor mutations, and, most importantly, patient choice.

\section{CLINICAL QUESTION B1}

What is the most effective second-line therapy for patients with stage IV NSCLC with negative or unknown EGFR/ALK status and NSCC?

\section{Recommendation B1}

For patients with advanced NSCLC, NSCC, negative or unknown EGFR/ALK status, and adequate PS, when disease has progressed during or after first-line platinum-based therapy, docetaxel, erlotinib, gefitinib, or pemetrexed is acceptable as second-line therapy (type: evidence based, benefits outweigh harms; evidence quality: high; strength of recommendation: strong).

Literature review update and analysis. Recommendations B1 and B2 represent a separation by histology of the 2009 recommendation. ${ }^{1}$ There has been no change to the content of Recommendation B1. Most of the trials in the systematic review did not find differences between the four agents that this guideline presents as second-line options. The trials found continue to support this recommendation for treatment with docetaxel, erlotinib, gefitinib, or pemetrexed. There were four trials of erlotinib versus chemotherapy. ${ }^{41,46,93,94}$ One study that compared pemetrexed and erlotinib did not find significant efficacy differences but did find a higher rate of hematologic adverse effects in the pemetrexed arm (neutropenia: $P=.001$; thrombocytopenia: $P=.013$; anemia: $P=.001) .{ }^{93}$ One trial performed a direct comparison of erlotinib versus docetaxel for a population with wildtype EGFR. The participants who received chemotherapy experienced longer OS compared with those who received erlotinib (8.2 $v 5.4$ months; $P=.10$ ). PFS was 0.5 months longer. Expected chemotherapy adverse effects were more common in the docetaxel arm, and rash (but not diarrhea) occurred more frequently in the erlotinib arm. ${ }^{41}$ One study compared two different strategies for sequencing treatment - that is, first-line erlotinib followed by second-line chemotherapy (cisplatin plus gemcitabine) compared with first-line chemotherapy (cisplatin plus gemcitabine) followed by second-line erlotinib. Efficacy outcomes were lower with first-line erlotinib, but the differences were not statistically significant. Some hematologic adverse events were more frequent with first-line chemotherapy; as expected, rash occurred more often with first-line erlotinib. ${ }^{94}$ The TITAN (Tarceva in Treatment of Advanced NSCLC; ClinicalTrials.gov identifier NCT00556322) study, which compared erlotinib versus docetaxel 
or pemetrexed for patients with poor prognosis who had not received previous anti-EGFR therapy, did not show efficacy differences between these agents. Treatment-related serious adverse events more frequent with chemotherapy, although rash was more common with erlotinib. ${ }^{46}$

Gefitinib was compared with chemotherapy in three studies. $^{23,47,49}$ In one trial, ${ }^{47}$ PFS, but not OS, was higher with chemotherapy. Serious adverse events were more frequent with chemotherapy, although treatment-related deaths were more frequent among patients treated with gefitinib. ${ }^{47}$ There was no efficacy advantage in another trial ${ }^{23}$; overall adverse events more frequent with chemotherapy. ${ }^{23}$ In the last trial, ${ }^{49}$ PFS, but not OS, was longer with gefitinib versus pemetrexed, and serious adverse events more frequent with gefitinib.

Combinations have been investigated in the second-line setting; for example, one trial compared docetaxel plus carboplatin with docetaxel alone. ${ }^{67}$ Although PFS was statistically significantly longer at 0.7 months with the combination, the OS improvement (ie, 2.57 months longer) did not reach statistical significance. Adverse events were not uniformly less common in one arm versus the other. ${ }^{67}$ The individual patient data meta-analysis by Di Maio et $\mathrm{al}^{95}$ of single versus doublet therapy in the second-line setting found that "doublet chemotherapy as second-line treatment of advanced NSCLC significantly increases response rate and progression-free survival, but is more toxic and does not improve overall survival compared with single-agent." 95 (p1836)

Other trials of agents not recommended in the previous version of this ASCO guideline for second-line therapy were found in the updated systematic review. When compared with the agents previously recommended, as well as those recommended in this update (ie, docetaxel, erlotinib, gefitinib, or pemetrexed), the new agents did not show OS benefits. These interventions include afatinib, ${ }^{15}$ aflibercept,${ }^{62}$ cetuximab, ${ }^{45}$ erlotinib plus bevacizumab, ${ }^{48,50}$ icotinib, ${ }^{48}$ nintedanib, ${ }^{64}$ sunitinib, ${ }^{65}$ vandetanib plus docetaxel, ${ }^{63}$ vandetanib plus erlotinib, ${ }^{51}$ vandetanib plus pemetrexed, ${ }^{96}$ and vinflunine. ${ }^{97}$

One trial tested a new vascular endothelial growth factor inhibitor for NSCLC, ramucirumab (plus docetaxel); the intervention arm experienced longer PFS (by 1.5 months) and OS (by 1.4 months), both statistically significant. Hematologic adverse events were more frequent with ramucirumab plus docetaxel, as were other adverse events, such as diarrhea, dyspnea, and fatigue. ${ }^{57}$ On December 12, 2014, the FDA approved ramucirumab for use in combination with docetaxel for the treatment of patients with metastatic NSCLC who experience disease progression during or after platinum-based chemotherapy; the drug is also approved for treatment of gastroesophageal junction adenocarcinoma, and the label carries a blackbox warning for hemorrhage. ${ }^{97 a}$

Clinical interpretation. Clinical trials support the use of singleagent therapy for patients with relapsed nonsquamous NSCLC after first-line chemotherapy. In the absence of EGFR/ALK mutations, chemotherapy may be a preferable approach. Patients with unknown EGFR/ALK status who have clinical demographics seen commonly in patients with gene mutations (young, female, Asian, and nonsmoking) may be better served with targeted drugs such as erlotinib or gefitinib. In the IPASS trial comparing gefitinib with carboplatin plus paclitaxel, in the subgroup of patients with unknown EGFR mutation status, there were statistically significantly longer PFS and higher response rates. ${ }^{61}$ Future efforts to fully characterize tumor biology and molecular subtype may include less invasive liquid biopsies of circulation tumor cells or DNA in the blood or other bodily fluids, which may reduce the incidence of unknown status.

Patients with nonsquamous histology who have not received pemetrexed therapy in the first-line setting may benefit from receiving pemetrexed in the second-line setting. This recommendation does not include gemcitabine as an option, because evidence was not found in the systematic review. There is weak evidence from studies that did not meet the study design inclusion criteria.

There is no definite evidence that combination therapy is superior, but it may be more toxic. Therefore, single-agent therapy is preferred in the second-line setting.

The role for vascular endothelial growth factor inhibitor therapy in the second-line setting is not clear. An early clinical trial showed a benefit for ramucirumab when administered with docetaxel compared with docetaxel alone, with a 1.4-month OS advantage. Patients with EGFR or ALK genomic tumor aberrations or mutations are most appropriately treated with FDA-approved agents targeting those aberrations before receiving ramucirumab. Whether this benefit will stand up to further testing is unclear.

\section{CLINICAL QUESTION B2}

What is the most effective second-line therapy for patients with stage IV NSCLC with negative or unknown EGFR/ALK status and SCC?

\section{Recommendation B2}

For patients with advanced NSCLC, SCC, negative or unknown EGFR/ALK status, and adequate PS, when disease has progressed during or after first-line platinum-based therapy, docetaxel, erlotinib, or gefitinib is acceptable as second-line therapy (type: evidence based, benefits outweigh harms; evidence quality: high; strength of recommendation: strong).

Literature review update and analysis. Most second-line studies in this systematic review included patients with SCC. Because there is evidence that pemetrexed is less effective for patients whose tumors have SCC histology, pemetrexed is included only in the NSCC recommendation (Recommendation B1). A trial of pemetrexed and erlotinib was amended, after the results of the trial by Scagliotti et $\mathrm{al}^{68}$ became available, to exclude patients with SCC; however, $21.7 \%$ to $23.5 \%$ of participants had SCC, and the investigators analyzed results according to histology. No significant differences in OS were found for participants with SCC, but TTP was longer with erlotinib (both findings were identified in exploratory analyses by histology; OS: $P=$ .006). ${ }^{93}$ A similar protocol amendment occurred in the TITAN trial, in which $35 \%$ to $38 \%$ of participants had SCC; however, participants were not stratified according to histology, and analyses by histology were not preplanned. ${ }^{46}$

A phase II trial of single-agent nivolumab was published after the systematic review; the study involved patients with SCC who had received $\geq$ two prior regimens. ${ }^{98}$ Nivolumab is an anti-programmed death receptor-1 (anti-PD-1) immune checkpoint inhibitor. It is thought to block the ability of a tumor cell to evade immune surveillance. The primary end point was overall response rate, which occurred in $17(14.5 \%$ ) of 117 patients (95\% CI 8.7 to 22.2 ). Median time to response was 3.3 months; median duration of response had not been reached at the time of publication. Adverse effects included dyspnea, fatigue, pneumonitis, diarrhea, musculoskeletal pain, and 
severe immune-mediated adverse effects ${ }^{98,99} ; 59 \%$ of patients experienced serious adverse events. ${ }^{100}$

On March 14, 2015, the FDA approved nivolumab for the treatment of patients with metastatic squamous cell NSCLC with disease progression who had received $\geq$ one prior platinum-based regimen on the basis of an RCT with 272 participants, in which patients were randomly assigned to receive single-agent nivolumab versus docetaxel. Median OS was 9.2 versus 6 months, favoring nivolumab (HR, 0.59 ; $95 \%$ CI, 0.44 to $0.79 ; P<.001$ ). This trial was published while this ASCO guideline update was in press; therefore, the final impact cannot yet be determined. ${ }^{101}$ The Update Committee awaits fuller data on adverse events before full incorporation into this guideline.

Clinical interpretation. Single-agent therapy is appropriate for patients with SCC in the second-line setting. These patients are unlikely to harbor EGFR/ALK gene mutations and may benefit from chemotherapy rather than targeted therapy with an EGFR TKI. Since the systematic review was performed for this guideline, nivolumab has emerged for patients with SCC in the second- and third-line settings who experience progression during or after platinum-based therapy. ${ }^{100}$ The Update Committee will consider a future guideline revision regarding the published phase III data (see Methodology Supplement: Revision Dates_-The SIGNALS Approach to Guideline Updating). Nonetheless, there is no absolute preference for chemotherapy versus targeted therapy.

\section{CLINICAL QUESTION B3.a}

What is the most effective second-line therapy for patients with stage IV NSCLC with a sensitizing EGFR mutation who received a first-line EGFR TKI and experienced disease progression?

\section{Recommendation B3.a}

For patients with a sensitizing EGFR mutation who did not respond to a first-line EGFR TKI, combination cytotoxic chemotherapy is recommended (Recommendation A2), following the first-line recommendations for patients with NSCC (type: informal consensus, benefits outweigh harms; evidence quality: intermediate; strength of recommendation: strong).

Literature review update and analysis. Given that there were no data meeting the inclusion criteria to inform this question, the Update Committee relied on clinical experience, training, and judgment to formulate this recommendation. There have been no prospective, randomized studies investigating the efficacy of second-line chemotherapy in patients with EGFR mutations who have responded to a first-line EGFR TKI. A subset analysis of the IPASS study, in which patients with adenocarcinoma of the lung were randomly assigned to receive gefitinib or carboplatin plus paclitaxel, demonstrated no difference in OS in either the EGFR mutation-positive arm or the EGFR mutation-negative arm. Of patients with EGFR mutation-positive NSCLC who were randomly assigned to carboplatin plus paclitaxel, $64.3 \%$ subsequently received EGFR TKIs. OS for the patients who had EGFR-positive disease was 21.6 months in the gefitinib arm and 21.9 months in the chemotherapy arm (HR, 1.00; 95\% CI, 0.76 to 1.33$).{ }^{30}$ Similarly, another phase III study of gefitinib versus carboplatin plus paclitaxel in patients with EGFR-sensitizing mutations also found an improvement in PFS but not OS, again presumably secondarily to crossover to chemotherapy in the gefitinib arm. Neither study reported the survival of patients who did or did not experience an initial response to gefitinib..$^{20,21}$
In the trial by Gridelli et al, ${ }^{102}$ which was stopped early and is discussed under Recommendation B1, participants were unselected for EGFR mutation status; $13.8 \%$ of the participants in the intervention arm and $14.6 \%$ in the control arm had EGFR mutation-positive disease. Outcomes were worse with first-line erlotinib, followed by an immediate switch to chemotherapy at progression. There was crossover in this study, so the authors could not analyze the association of mutation status with OS.

Other studies have randomly assigned patients with EGFR mutations to a first-line EGFR TKI or cytotoxic chemotherapy and found that PFS was improved in those who received the EGFR TKI. However, final results of OS have not been reported for most studies; therefore, the outcomes of those patients who crossed over to chemotherapy have not been yet analyzed. ${ }^{11,13,20,29,94}$

Clinical interpretation. Given that there are no data to suggest that patients with EGFR mutations for whom EGFR TKIs fail do poorly with chemotherapy, the Update Committee opted to make a consensus recommendation for chemotherapy as a secondline treatment.

\section{CLINICAL QUESTION B3.b}

What is the most effective second-line therapy for patients with stage IV NSCLC with a sensitizing EGFR mutation who received a first-line EGFR TKI and experienced disease progression after an initial response?

\section{Recommendation B3.b}

Patients who received an EGFR TKI in the first-line setting, had an initial response, and subsequently experienced disease progression may be switched to chemotherapy or another EGFR TKI as secondline therapy (type: informal consensus, balance of benefits and harms; evidence quality: low; strength of recommendation: weak).

Literature review update and analysis. Given that there were no data meeting the inclusion criteria to inform this question, the Update Committee relied on clinical experience, training, and judgment to formulate this recommendation. Afatinib has shown preclinical activity in EGFR-mutant models with the exon 20 T790M mutation, which has been shown to confer resistance to EGFR-reversible TKIs. A phase IIB/III randomized clinical trial (LUX-Lung 1$)^{15}$ investigated the role of afatinib for patients whose disease had progressed with both chemotherapy and an EGFR inhibitor. This study included many participants whose tumors had developed resistance to treatment with an EGFR TKI; however, EGFR mutation status was not an eligibility criterion. The study found no improvement in the primary end point of OS between patients randomly assigned to afatinib and those randomly assigned to placebo, although PFS was longer in the afatinib group ( $3.3 v 1.1$ months; $\mathrm{HR}, 0.38$; $95 \% \mathrm{CI}, 0.31$ to $0.48 ; P$ $<.001)$. Response rate was $7 \%$ versus $0.5 \%$. Ninety-six patients had tumors that were positive for EGFR mutations. Among these 96 patients, PFS was 3.3 months for those who received afatinib and 1.0 month for those who received placebo ( $\mathrm{HR}, 0.55 ; 95 \% \mathrm{CI}$, 0.31 to $0.85 ; P=.009) .{ }^{15}$

In a prespecified analysis, participants with a complete or partial response to a first-line EGFR TKI whose tumors also had known EGFR mutation test results (58 [88\%] of 66), the HR for PFS was significant (0.23), but the HR for OS was not (0.90) in the afatinib arm. Sixty-three percent of the patients in the afatinib 
group and $76 \%$ in the control group received $\geq$ one subsequent regimen (all mutation statuses). ${ }^{15}$

Clinical interpretation. There is a lack of conclusive data for treating this population, especially with a second TKI. In the afatinib trial, response rates in both arms were lower than in studies with chemotherapy; however, given the longer PFS, afatinib after gefitinib or erlotinib in patients with EGFR-sensitizing mutations who experienced an initial response may be an option.

There are indications that it is not beneficial to continue an EGFR inhibitor after acquired resistance. European Society for Medical Oncology results from IMPRESS (Iressa Mutation Positive Multicenter Treatment Beyond Progression Study; ClinicalTrials.gov identifier NCT01544179), in which the control arm, composed of patients with resistance to an EGFR TKI (gefitinib) and chemotherapy, continued to receive an EGFR inhibitor with chemotherapy, the addition of (or continuation) of the TKI did not add efficacy or adverse event benefits. These results have not yet been released in a peer-reviewed publication. ${ }^{102 a}$

\section{CLINICAL QUESTION B4}

What is the most effective second-line therapy for patients with stage IV NSCLC with ALK rearrangement with progression after firstline crizotinib?

\section{Recommendation B4}

Patients whose tumors have $A L K$ rearrangements and who received crizotinib in the first-line setting may be offered the option of chemotherapy (after first-line recommendations for patients with NSCC [see Recommendation A2]) or ceritinib in the second-line setting (chemotherapy: type: evidence based, benefits outweigh harms; evidence quality: high; strength of recommendation: strong; ceritinib: type: evidence based, benefits outweigh harms; evidence quality: intermediate; strength of recommendation: moderate).

Literature review update and analysis. Support for including ceritinib in this recommendation is based on FDA approval. There are no published phase III trials on ceritinib (or other studies that met inclusion criteria for this systematic review). The FDA approved ceritinib on the basis of a phase I single-arm trial. ${ }^{102 b}$ The results were published, ${ }^{42}$ and updated results were presented as an abstract at the 2014 ASCO Annual Meeting, ${ }^{43}$ both outside of the date parameters of the systematic review for this guideline update. The noncomparative study reported by Kim et $\mathrm{al}^{43}$ included 163 participants who had received first-line crizotinib and 83 who had not. PFS was 6.9 months (95\% CI, 5.39 to 8.41 ) for those pretreated with crizotinib, and the overall response rate was 54.6 (95\% CI, 46.6 to 62.4). PFS in the population of patients who were not pretreated was not estimable at the time of the presentation. Grade 3 to 4 adverse effects in all patients included increases in ALT, AST, and glucose, as well as diarrhea. In a report by Shaw et $\mathrm{al}^{42} 80$ of 122 of previously treated patients had received crizotinib, and the response rate with ceritinib was 56\% (95\% CI, 45 to 67). At the subsequently approved dose of $750 \mathrm{mg}$ once daily, the response rate was 59\% (95\% CI, 47 to 70). Grade 3 to 4 adverse effects included increased ALT and increased AST levels, diarrhea, and increased lipase levels. There were four cases of interstitial lung disease. In the group of 80 patients who had received crizotinib, median PFS was 6.9 months (95\% CI, 5.3 to 8.8). In an interim analysis, 12-month OS was $65 \%$ for all participants. ${ }^{42}$ The FDA-approved label for patients who receive ceritinib who have previously re- ceived crizotinib states that "continued approval for this indication may be contingent on verification and description of clinical benefit in confirmatory trials."

Clinical interpretation. Given that there are not any published phase III trials for patients whose tumors have $A L K$ rearrangements and who received crizotinib in the first-line setting, ceritinib is an option based on early clinical trials. Chemotherapy may still be appropriate in the absence of phase III data. This guideline update recommends crizotinib in the first line for patients with $A L K$ rearrangements, and current FDA approval allows for initial therapy with crizotinib for patients with stage IV NSCLC harboring ALK mutations (see Recommendation A5). Patients whose cancers initially respond to crizotinib often experience a relapse of the disease. ${ }^{56}$

The optimal treatment for patients with $A L K$ mutations who experience disease progression with crizotinib is rapidly evolving. There is no high-level evidence to guide the physician or patient in this situation. Standard cytotoxic chemotherapy remains a reasonable option for all patients who meet guidelines for first-line treatment with cytotoxic chemotherapy (see Recommendation A1), especially if the patient experienced significant toxicity with crizotinib.

However, the recent FDA approval of ceritinib for patients with $A L K$-positive NSCLC who experience disease progression with crizotinib is a potentially practice-changing event. Ceritinib is an oral agent targeting $A L K$, with much higher potency than crizotinib. Toxicities (and durability) seem similar to those of crizotinib, including a low risk for serious pneumonitis; long-term outcomes are still under study. This agent will likely be the choice of patients and physicians over chemotherapy in the second line for patients who tolerated crizotinib but experienced disease progression. The Update Committee awaits more data.

\section{CLINICAL QUESTION B5}

What is the optimal second-line treatment for elderly patients with stage IV NSCLC?

\section{Recommendation B5}

The evidence does not support the selection of a specific secondline chemotherapy drug or combination based on age alone. This recommendation has not changed. As stated in Recommendation A8, age alone is not a contraindication to chemotherapy for NSCLC.

\section{CLINICAL QUESTION C}

Is there a role for third-line therapy or beyond in the treatment of stage IV NSCLC?

\section{Recommendation C1}

When disease progresses during or after second-line chemotherapy, treatment with erlotinib may be recommended as third-line therapy for patients with a PS of 0 to 3 who have not received prior erlotinib or gefitinib (no change).

Literature review update and analysis. No studies were found to recommend a change from the previous recommendation. Some of the second-line studies included patients who had received $>$ two previous regimens. ${ }^{15,23,47,48,51,65}$

Clinical interpretation. Future use of new treatments, including new targeted therapies or immunotherapy, will await more data. 


\section{Recommendation C2}

Data are not sufficient to make a recommendation for or against using cytotoxic drugs as third-line therapy; patients should consider experimental treatment, clinical trials, and continued best supportive (palliative) care (no change from previous recommendations).

There are no data that suggest a benefit to additional chemotherapy compared with alternative forms of non-chemotherapybased care, such as hospice or palliative care. In distinction from chemotherapy after the second-line setting, palliative care has been associated with equal ${ }^{103-106}$ or longer ${ }^{107-109}$ survival in randomized and nonrandomized ${ }^{110}$ trials of patients with advanced cancer. These studies have also reported better QoL, less depression and anxiety, and less caregiver distress with palliative care. In the largest trial of concurrent palliative care plus oncology care versus oncology care alone, patients treated by their oncologists alone had less prognostic awareness that they could not be cured, received more intravenous chemotherapy in the last 60 days of life, used hospice less often and for shorter periods, and died 2.7 months sooner than those who used palliative care. ${ }^{111}$

There are no data to suggest that the benefits of continued chemotherapy outweigh the risks; there some evidence that continued chemotherapy may do harm, including the foregoing of advance care planning, palliative care consultation, and early use of hospice. ASCO recommends concurrent palliative care alongside usual oncology care from the onset of diagnosis of advanced lung cancer ${ }^{5}$ because the clinical case is so strong. ${ }^{112}$ Further discussion of palliative care is found in the Discussion section.

\section{DISCUSSION}

\section{Cetuximab}

Previous versions of this guideline $\left(2009^{113}\right.$ and $\left.2011^{2}\right)$ included a recommendation that clinicians "consider addition of cetuximab to cisplatin/vinorelbine in first-line therapy in patients with EGFRpositive tumor as measured by immunohistochemistry." $2(\mathrm{p} 3)$ The phase III FLEX (First-Line Erbitux in Lung Cancer; ClinicalTrials.gov identifier NCT00148798) trial on which the previous guideline recommendation was based included an entry criterion of one immunohistochemistry-positive cell. In the intervening years, this method of assessing EGFR expression has not been shown to be feasible. Cetuximab is not approved by the regulatory agencies in the United States, Canada, or Europe for patients with NSCLC. The BMS099 trial of cetuximab in addition to taxane plus carboplatin versus taxane plus carboplatin resulted in a shorter PFS with cetuximab and some adverse effects. ${ }^{71}$ Therefore, the Update Committee decided to remove this recommendation from the current update.

\section{Palliative Care}

This stage IV guideline update includes both a discussion on the updated evidence in disease-modifying therapies since the 2011 systematic review was completed and a discussion of palliative care, in this section, to complement the ASCO 2012 provisional clinical opinion. $^{5}$

In 2012, ASCO reviewed the evidence from an RCT showing an increase in median OS for patients receiving palliative care services concurrently with disease-modifying therapy. The participants in that study had stage IV NSCLC. This confirmed the evidence from multiple randomized trials that included patients with cancer who showed an improvement in symptoms, including less anxiety and depression, higher satisfaction, less aggressive end-of-life care, and less caregiver distress. ${ }^{108}$ In addition, a cluster RCT published since the provisional clinical opinion, which included participants with NSCLC, showed important improvements in QoL, symptoms, and caregiver distress. ${ }^{106}$ It is important to note that these studies and others in the ASCO provisional clinical opinion used a palliative care team in addition to usual oncology care, suggesting the benefits of referral.

For patients with stage IV NSCLC lung cancer, as well as for those with other solid tumors with distant metastases, it is incumbent on the clinicians and patients to consider the goals of interventions offered when this diagnosis is made. This includes not only disease-modifying therapy but also assessment of patient needs for supportive care, symptom management, symptom relief, and psychosocial interventions and patient preferences and values and other interventions that may be offered under various umbrellas depending on the setting.

Assessment, diagnosis, and relief of pain and other distressing symptoms, psychological and social support before death, consideration of interventions that the patient does and does not want, and clinician self-care are all important aspects of care for patients with incurable disease. ${ }^{114}$ Attention to the ratio of benefits to harms is crucial in communication between the clinician and patient, as discussed in the 2009 ASCO NSCLC guideline. ${ }^{113}$ These services may be provided by the oncology team alone or in collaboration with or referral to palliative care specialists.

At a minimum, such concurrent care should include discussion of advance care planning using the "ask, tell, ask" method; a structured symptom assessment, such as with the Memorial or Edmonton Symptom Assessment Scale (with special attention to depression); a structured goals-of-care discussion; a structured inquiry about spiritual care, such as with the FICA (Faith, Importance, Community, Actions); and an assessment of caregiver needs. ${ }^{115}$ Readers are referred to ASCO guidelines on prevention and management of chemotherapyinduced peripheral neuropathy ${ }^{116}$; screening, assessment, and management of fatigue $^{117}$; and screening, assessment, and care of anxiety and depressive symptoms. ${ }^{118}$ Hospice use of any type and duration is strongly associated with better OS in patients with advanced cancer, ${ }^{119}$ including those specifically with lung cancer. ${ }^{120}$ Therefore, a hospice information visit is recommended when the patient has approximately 6 months to live. We also suggest specific language, based on well-designed clinical trials, to help with the planned transition to hospice and a specific statement of nonabandonment, such as "whatever action we do take, and however that develops, we will continue to take good care of you; we will be with you all the way" (personal communication, T.J. Smith, April 2015), ${ }^{121}$ which have been proven to help with the transition to end-of-life care.

There are obstacles to integrating palliative care. "These challenges include the need for a cultural or paradigm shift, potential barriers to accessing services, variability of practice setting, and initial increases in cost of implementation. As a community, we need to overcome the perception of the cure/care dichotomy and recognize that palliative care belongs throughout the continuum of care." ${ }^{122(\mathrm{p} 3335)}$ Studies mentioned here and other evidence will be addressed further in future guidelines from the ASCO Supportive Care Guidelines Advisory Group. 


\section{PATIENT AND CLINICIAN COMMUNICATION}

The 2009 full version of this guideline contained an extensive discussion of patient-clinician communication. ${ }^{113}$ An environmental scan of related literature published since 2009 found that patients with NSCLC continue to grapple with complex medical, psychological, and social issues. For example, in the study of early palliative care for patients with NSCLC discussed in the ASCO provisional clinical opinion, 14\% of 151 patients had major depressive syndrome, which significantly predicted worse survival. ${ }^{123}$ A stigma is connected with lung cancer because of the association with smoking; this stigma increases depression and decreases QoL. ${ }^{124}$ Because of a misunderstanding about prognosis, one third of patients (46 of 145) reported that their cancer was curable at baseline, and a majority of patients (86 of 124) endorsed getting rid of all of the cancer as a goal of therapy. ${ }^{125}$ Insufficient time and training of physicians and such patient misconceptions complicate communication. Some patients may prefer not to know their prognosis, so it is important to ask: "What do you know and what do you want to know?"

A dedicated session with the patient and preferably a caregiver should take place immediately after diagnosis to honestly and completely discuss the diagnosis, treatment (benefits and risks), prognosis, and palliative care concurrent with any anticancer therapy. Physicians should "talk with patients about palliative care and end of life preferences early on, not in the weeks before death." ${ }^{126(\mathrm{pSR} 14)}$ In a lecture to medical students at the University of Virginia, a physician with stage IV colon cancer said, "We need to sketch for such persons, preferably in advance of a crisis, what the likely course of the disease is both with and without medical or surgical treatment and describe our idea of the better choice." ${ }^{127(p 7)}$

A new discussion on risks, benefits, and prognosis should be initiated before each new therapy (especially third line and beyond) is considered, with palliative care only listed as an option. This is particularly important when a patient's PS falls below PS 2. "In medical consultations, patients experience a double-need: to know and understand and to feel known and understood."121(p3274),127 There are more details on patient communication and palliative care in the Palliative Care section of the Discussion. The Data Supplement to this current version of the guideline suggests language for clinicians on presenting benefits and risks of NSCLC treatment to consider using in consultations.

\section{HEALTH DISPARITIES}

Although ASCO clinical practice guidelines represent expert recommendations on the best practices in disease management to provide the highest level of cancer care, it is important to note that many patients have limited access to medical care, and many disparities persist. An environmental literature search was conducted for reviews on health disparities and lung cancer published between the years 2008 and 2014. The results show that disparities in race, ${ }^{128-131}$ sex, ${ }^{132}$ socioeconomic status, ${ }^{132-135}$ level of education, ${ }^{136}$ residence, ${ }^{128,136}$ and insurance status, ${ }^{137-139}$ among other factors, continue to be associated with outcomes such as mortality, ${ }^{128,140}$ incidence, ${ }^{137,140}$ stage at diagnosis, and timely receipt of recommended treatment ${ }^{129,131}$ for patients with NSCLC.
Black men continue to have higher incidence rates of lung cancer than white non-Hispanic men. ${ }^{141}$ Race is associated with lack of any treatment, lack of timely treatment, and lack of appropriate treatment. ${ }^{129,132,142}$ Elderly and female patients also receive disparate treatment. ${ }^{132}$ Socioeconomic factors, insurance coverage, and residential segregation also play a role in lung cancer disparities. ${ }^{128,136-138}$ Socioeconomic status is likely an independent prognostic factor for lung cancer survival. ${ }^{134}$ Death rates in lung cancer are higher for black men than white men, ${ }^{141}$ as well as for American Indians and Alaska natives. ${ }^{143}$ However, as stated in the 2009 guideline, ${ }^{113}$ equal access to care can provide similar outcomes.

Potential changes could come from research involving physicians, patients of color, and patients from various socioeconomic backgrounds, especially with regard to successful interventions, health system strengthening, improvements in health education, improved patient-clinician communication, quality standards, tracking of patients, and navigators. ${ }^{130,144,145}$

In summary, racial, ethnic, and socioeconomic disparities in health care contribute significantly to health disparities in the United States. Patients with cancer who are members of racial or ethnic minorities may disproportionately experience comorbidities, experience more substantial obstacles to receiving care, be more likely lack insurance, and face a greater risk of receiving poor-quality care than other Americans. ${ }^{140,141,146,147}$ Many other patients may lack access to care because of geographic location and distance from appropriate treatment facilities. Awareness of these disparities in access to care should be considered in the context of this clinical practice guideline, and health care providers should strive to deliver the highest level of cancer care to vulnerable populations. More information regarding the review is provided in the Data Supplement.

\section{Mccs}

Creating evidence-based recommendations to inform treatment of patients with additional chronic conditions, a situation in which the patient may have $\geq$ two such conditions-referred to as MCCs - is challenging. Patients with NSCLC often have MCCs; the five most commonly encountered chronic conditions in patients with lung cancer irrespective of age include hypertension, chronic obstructive pulmonary disease, hyperlipidemia, ischemic heart disease, and anemia ${ }^{148}$ (see Data Supplement for other common MCCs). Each of those listed here is reported with a frequency $>50 \%$ in patients age $\geq 65$ years, with the prevalence of hypertension, hyperlipidemia, and ischemic heart disease being significantly greater in the older age group. In addition, almost one third of older patients have diabetes, heart failure, and chronic kidney disease, which have significant repercussions on treatment planning, administration, and tolerance. There are various validated tools to study comorbidity, particularly in the geriatric literature; these include the Charlson comorbidity index, the Cumulative Illness Rating Scale, the Older Americans Resources and Services (OARS) Multidimensional Functional Assessment Questionnaire, and the Adult Comorbidity Evaluation-27 Index (latter index has been validated irrespective of age). ${ }^{149-152}$ MCCs are most relevant for treatment of older adults and those with $\mathrm{PS} \geq 2$. Although there have been several therapeutic trials in advanced NSCLC that have 
been limited to these populations, few have reported the specific association of MCCs with toxicity and efficacy of treatment as a distinct end point. MCCs are associated with greater risk of hematologic toxicity and infectious complications in patients with advanced NSCLC treated with platinum-based chemotherapy. MCCs are also associated with early treatment discontinuation. Patients with MCCs make up a complex and heterogeneous population, which makes it difficult to account for all of the possible permutations involved in developing specific recommendations for care. There are few data regarding the impact of specific chronic conditions on outcomes (chemotherapy-related adverse events and survival) in advanced NSCLC. Most available data regarding MCCs in advanced NSCLC are collected and reported as comorbidity. ${ }^{19}$ In addition, the best available evidence for treating index conditions often comes from clinical trials, the study selection criteria of which may exclude these patients to avoid potential interaction effects or confounding of results associated with MCCs. As a result, the reliability of outcome data from these studies may be limited, thereby creating constraints against making recommendations for care in this heterogeneous patient population.

Because many patients for whom guideline recommendations apply present with MCCs, any treatment plan needs to take into account the complexity and uncertainty created by the presence of MCCs and highlight the importance of shared decision making regarding guideline use and implementation. Therefore, in consideration of recommended care for the target index condition, clinicians should review all other chronic conditions present in the patient and take those conditions into account when formulating treatment and follow-up plans (see Data Supplement 6 for more information).

\section{GUIDELINE IMPLEMENTATION}

ASCO guidelines are developed for implementation across health settings. Barriers to implementation include the need to increase awareness of the guideline recommendations among front-line practitioners, survivors of cancer, and caregivers and the need to provide adequate services in the face of limited resources. The guideline Bottom Line Box was designed to facilitate implementation of recommendations. This guideline will be distributed widely through the ASCO Practice Guideline Implementation Network. ASCO guidelines are posted on the ASCO Web site and are also often published in Journal of Clinical Oncology and Journal of Oncology Practice.

\section{LIMITATIONS OF RESEARCH}

There are not yet sufficient objective tools available to clinicians to determine which patients would benefit from and tolerate combined therapy in comparison with single-agent chemotherapy. The data informing chemotherapy decisions for patients with PS 2 are insufficient. There are not enough data on patients with large-cell neuroendocrine carcinoma or enough mature data on ROS1 and crizotinib or on second-line treatment for patients who received first-line treatment with an EGFR TKI and experienced disease progression or for those who received an EGFR TKI and had an initial response. In addition, there are not enough mature data on adding pemetrexed to bevacizumab plus carboplatin; there has been only one phase III trial. ${ }^{153}$ ASCO believes that cancer clinical trials are vital to inform medical decisions and improve cancer care and that all patients should have the opportunity to participate.

\section{FUTURE DIRECTIONS}

As a result of the lack of data in certain areas, the Update Committee hopes new results will inform future versions of this guideline, including in the following specific areas:

- Results of studies comparing gefitinib with afatinib and gefitinib with dacomitinib

- Further study of the optimal integration of chemotherapy and targeted agents in the treatment of patients with gene mutations in various lines of therapy

- Further study of third-line therapy

- Results from examples of ongoing studies on resistance mechanics and new agents (note this is not comprehensive list):

- Third-generation EGFR inhibitors, ${ }^{154,155}$ for example, AZD9291 (AURA3 trial [AZD9291 v platinum-based doublet chemotherapy in locally advanced or metastatic NSCLC]; ClinicalTrials.gov identifier NCT02151981) and CO1686, now in phase II trials (TIGER-2 [Open Label Safety and Efficacy Study of CO-1686 in Patients With T790M Positive NSCLC Who Have Failed One Previous EGFR-Directed TKI]; ClinicalTrials.gov identifier NCT0214799d0; TIGER-1 [Safety and Efficacy Study of Rociletinib (CO-1686) or Erlotinib in Patients Eith EGFR Mutant NSCLC Who Have Not Had Any Previous EGFR Directed Therapy]; ClinicalTrials.gov identifier NCT02186301; and TIGER-X [Study to Evaluate Safety, Pharmacokinetics, and Efficacy of CO-1686 in Previously Treated Mutant Epidermal Growth Factor Receptor (EGFR) Non-Small Cell Lung Cancer (NSCLC)]; ClinicalTrials.gov NCT01526928)

- Ramucirumab; ongoing trials in the second-line setting include a phase II trial (Study of Docetaxel and Ramucirumab Versus Docetaxel and Placebo in the Treatment of Stage IV Non-Small Cell Lung Cancer; ClinicalTrials.gov identifier NCT01703091), a phase III trial (Study of Chemotherapy and Ramucirumab Versus Chemotherapy Alone in Second Line Nonsmall Cell Lung Cancer Participants Who Received Prior First Line Platinum Based Chemotherapy; ClinicalTrials.gov identifier NCT01168973), and a phase II trial (Study of Pemetrexed and Carboplatin/ Cisplatin or Gemcitabine and Carboplatin/Cisplatin With or Without IMC-1121B in Patients Previously Untreated With Recurrent or Advanced Non-Small Cell Lung Cancer; ClinicalTrials.gov identifier NCT01160744)

- Results of a phase III trial of ceritinib for those who have previously received crizotinib and chemotherapy (Clinical Trials.gov identifier NCT01828112)

- Immunotherapy, such as PD-1 or PD-1 ligand (PD-L1) inhibitors 
- Nivolumab in NSCC, for example, in the CheckMate trials (Open-Label, Randomized, Phase 3 Trial of Nivolumab Versus Investigator's Choice Chemotherapy As First-Line Therapy for Stage IV or Recurrent PD-L1+ Non-Small Cell Lung Cancer [CheckMate 026]; Clinical Trials.gov identifier NCT02041533 and Safety Trial of Nivolumab [BMS-936558] in Subjects With Advanced or Metastatic Non-Small Cell Lung Cancer Who Have Progressed During or After Receiving at Least One Prior Systemic Regimen [CheckMate 153]; ClinicalTrials.gov identifier NCT02066636)

- Pembrolizumab, ${ }^{156}$ for example, in the KEYNOTE trials (Study of MK-3475 [Pembrolizumab] Versus PlatinumBased Chemotherapy for Participants With PD-L1-Positive Advanced or Metastatic Nonsmall Cell Lung Cancer [MK3475-042/KEYNOTE-042]; ClinicalTrials.gov identifier NCT02220894 and Study of Pembrolizumab [MK-3475] Compared With Platinum-Based Chemotherapies in Participants With Metastatic Non-Small Cell Lung Cancer [MK3475-024/KEYNOTE-024] ClinicalTrials.gov identifier NCT02142738)

\section{ADDITIONAL RESOURCES}

More information, including a Data Supplement with additional evidence tables, a Methodology Supplement with information about evidence quality and strength of recommendations, slide sets, and clinical tools and resources, is available at http://www.asco.org/guidelines/ nsclc. Patient information is available at http://www.cancer.net.

\section{AUTHORS' DISCLOSURES OF POTENTIAL CONFLICTS OF INTEREST}

Disclosures provided by the authors are available with this article at www.jco.org.

\section{AUTHOR CONTRIBUTIONS}

\author{
Administrative support: Sarah Temin \\ Manuscript writing: All authors \\ Final approval of manuscript: All authors
}

\section{REFERENCES}

1. Azzoli CG, Baker S Jr, Temin S, et al: American Society of Clinical Oncology clinical practice guideline update on chemotherapy for stage IV non-small-cell lung cancer. J Clin Oncol 27:62516266, 2009

2. Azzoli CG, Temin S, Aliff T, et al: 2011 Focused update of 2009 American Society of Clinical Oncology clinical practice guideline update on chemotherapy for stage IV non-small-cell lung cancer. J Clin Oncol 29:3825-3831, 2011

3. Leighl NB, Rekhtman N, Biermann WA, et al: Molecular testing for selection of patients with lung cancer for epidermal growth factor receptor and anaplastic lymphoma kinase tyrosine kinase inhibitors: American Society of Clinical Oncology endorsement of the College of American Pathologists/ International Association for the Study of Lung Cancer/Association for Molecular Pathology guideline. J Clin Oncol 32:3673-3679, 2014

4. Rami-Porta R, Bolejack V, Giroux DJ, et al: The IASLC lung cancer staging project: The new database to inform the eighth edition of the TNM classification of lung cancer. J Thorac Oncol 9:16181624, 2014

5. Smith TJ, Temin S, Alesi ER, et al: American Society of Clinical Oncology provisional clinical opinion: The integration of palliative care into standard oncology care. J Clin Oncol 30:880-887, 2012

6. Mok T, Kim DW, Wu YL: First-line crizotinib versus pemetrexed-cisplatin or pemetrexed-carboplatin in patients (pts) with advanced ALK-positive non-squamous non-small cell lung cancer (NSCLC): Results of a phase III study (PROFILE 1014). J Clin Oncol 32:506s, 2014 (suppl 5s; abstr 8002)

7. Paz-Ares LG, de Marinis F, Dediu M, et al: PARAMOUNT: Final overall survival results of the phase III study of maintenance pemetrexed versus placebo immediately after induction treatment with pemetrexed plus cisplatin for advanced nonsquamous non-small-cell lung cancer. J Clin Oncol 31: 2895-2902, 2013
8. Paz-Ares L, de Marinis F, Dediu M, et al: Maintenance therapy with pemetrexed plus best supportive care versus placebo plus best supportive care after induction therapy with pemetrexed plus cisplatin for advanced non-squamous non-small-cell lung cancer (PARAMOUNT): A double-blind, phase 3, randomised controlled trial. Lancet Oncol 13:247255, 2012

9. Gridelli C, de Marinis F, Pujol JL, et al: Safety, resource use, and quality of life in paramount: A phase III study of maintenance pemetrexed versus placebo after induction pemetrexed plus cisplatin for advanced nonsquamous non-smallcell lung cancer. J Thorac Oncol 7:1713-1721, 2012

10. Di Maio M, Leighl NB, Gallo C, et al: Quality of life analysis of TORCH, a randomized trial testing first-line erlotinib followed by second-line cisplatin/ gemcitabine chemotherapy in advanced non-smallcell lung cancer. J Thorac Oncol 7:1830-1844, 2012

11. Sequist LV, Yang JC, Yamamoto $N$, et al: Phase III study of afatinib or cisplatin plus pemetrexed in patients with metastatic lung adenocarcinoma with EGFR mutations. J Clin Oncol 31:3327-3334, 2013

12. Yang JC, Hirsh V, Schuler $M$, et al: Symptom control and quality of life in LUX-Lung 3: A phase III study of afatinib or cisplatin/pemetrexed in patients with advanced lung adenocarcinoma with EGFR mutations. J Clin Oncol 31:3342-3350, 2013

13. Zhou C, Wu YL, Chen G, et al: Erlotinib versus chemotherapy as first-line treatment for patients with advanced EGFR mutation-positive nonsmall-cell lung cancer (OPTIMAL, CTONG-0802): A multicentre, open-label, randomised, phase 3 study. Lancet Oncol 12:735-742, 2011

14. Chen G, Feng J, Zhou C, et al: Quality of life (QoL) analyses from OPTIMAL (CTONG-0802), a phase III, randomised, open-label study of first-line erlotinib versus chemotherapy in patients with advanced EGFR mutation-positive non-small-cell lung cancer (NSCLC). Ann Oncol 24:1615-1622, 2013

15. Miller VA, Hirsh V, Cadranel J, et al: Afatinib versus placebo for patients with advanced, metastatic non-small-cell lung cancer after failure of erlotinib, gefitinib, or both, and one or two lines of chemotherapy (LUX-Lung 1): A phase 2b/3 randomised trial. Lancet Oncol 13:528-538, 2012

16. Hirsh V, Cadranel J, Cong XJ, et al: Symptom and quality of life benefit of afatinib in advanced non-small-cell lung cancer patients previously treated with erlotinib or gefitinib: Results of a randomized phase IIb/III trial (LUX-Lung 1). J Thorac Oncol 8:229-237, 2013

17. Gridelli $C$, Di Maio M: The role of pemetrexed as maintenance treatment in advanced NSCLC: A phase III randomized trial. Expert Opin Pharmacother 11:321-324, 2010

18. Grønberg $B H$, Bremnes RM, Fløtten $O$, et al: Phase III study by the Norwegian lung cancer study group: Pemetrexed plus carboplatin compared with gemcitabine plus carboplatin as first-line chemotherapy in advanced non-small-cell lung cancer. J Clin Oncol 27:3217-3224, 2009

19. Grønberg BH, Sundstrøm S, Kaasa $S$, et al: Influence of comorbidity on survival, toxicity and health-related quality of life in patients with advanced non-small-cell lung cancer receiving platinum-doublet chemotherapy. Eur J Cancer 46: 2225-2234, 2010

20. Maemondo $M$, Inoue $A$, Kobayashi $K$, et al: Gefitinib or chemotherapy for non-small-cell lung cancer with mutated EGFR. N Engl J Med 362:23802388, 2010

21. Inoue $A$, Kobayashi $K$, Maemondo $M$, et al: Updated overall survival results from a randomized phase III trial comparing gefitinib with carboplatinpaclitaxel for chemo-naïve non-small cell lung cancer with sensitive EGFR gene mutations (NEJ002). Ann Oncol 24:54-59, 2013

22. Oizumi S, Kobayashi K, Inoue A, et al: Quality of life with gefitinib in patients with EGFR-mutated non-small cell lung cancer: Quality of life analysis of North East Japan Study Group 002 trial. Oncologist 17:863-870, 2012

23. Maruyama $R$, Nishiwaki $Y$, Tamura $T$, et al: Phase III study, V-15-32, of gefitinib versus docetaxel in previously treated Japanese patients with non-small-cell lung cancer. J Clin Oncol 26:42444252, 2008 
24. Sekine $I$, Ichinose $Y$, Nishiwaki $Y$, et al: Quality of life and disease-related symptoms in previously treated Japanese patients with nonsmall-cell lung cancer: Results of a randomized phase III study (V-15-32) of gefitinib versus docetaxel. Ann Oncol 20:1483-1488, 2009

25. Socinski MA, Langer CJ, Okamoto I, et al: Safety and efficacy of weekly nabß-paclitaxel in combination with carboplatin as first-line therapy in elderly patients with advanced non-small-cell lung cancer. Ann Oncol 24:314-321, 2013

26. Socinski MA, Bondarenko I, Karaseva NA, et al: Weekly nab-paclitaxel in combination with carboplatin versus solvent-based paclitaxel plus carboplatin as first-line therapy in patients with advanced non-small-cell lung cancer: Final results of a phase III trial. J Clin Oncol 30:2055-2062, 2012

27. Stathopoulos GP, Antoniou D, Dimitroulis J et al: Comparison of liposomal cisplatin versus cisplatin in non-squamous cell non-small-cell lung cancer. Cancer Chemother Pharmacol 68:945-950, 2011

28. Stathopoulos GP, Antoniou D, Dimitroulis J, et al: Liposomal cisplatin combined with paclitaxe versus cisplatin and paclitaxel in non-small-cell lung cancer: A randomized phase III multicenter trial. Ann Oncol 21:2227-2232, 2010

29. Rosell R, Carcereny $E$, Gervais $R$, et al: Erlotinib versus standard chemotherapy as first-line treatment for European patients with advanced EGFR mutation-positive non-small-cell lung cancer (EURTAC): A multicentre, open-label, randomised phase 3 trial. Lancet Oncol 13:239-246, 2012

30. Fukuoka M, Wu YL, Thongprasert $S$, et al: Biomarker analyses and final overall survival results from a phase III, randomized, open-label, first-line study of gefitinib versus carboplatin/paclitaxel in clinically selected patients with advanced nonsmall-cell lung cancer in Asia (IPASS). J Clin Oncol 29:2866-2874, 2011

31. Wu YL, Lee JS, Thongprasert $S$, et al: Intercalated combination of chemotherapy and erlotinib for patients with advanced stage non-small-cell lung cancer (FASTACT-2): A randomised, double-blind trial. Lancet Oncol 14:777-786, 2013

32. Pirker R, Pereira JR, von Pawel J, et al: EGFR expression as a predictor of survival for first-line chemotherapy plus cetuximab in patients with advanced non-small-cell lung cancer: Analysis of data from the phase 3 FLEX study. Lancet Oncol 13:3342, 2012

33. Barlesi F, Scherpereel A, Rittmeyer A, et al: Randomized phase III trial of maintenance bevacizumab with or without pemetrexed after first-line induction with bevacizumab, cisplatin, and pemetrexed in advanced nonsquamous non-small-cell lung cancer: AVAPERL (MO22089). J Clin Oncol 31:3004-3011, 2013

34. Gaafar RM, Surmont VF, Scagliotti GV, et al: A double-blind, randomised, placebo-controlled phase III intergroup study of gefitinib in patients with advanced NSCLC, non-progressing after first line platinum-based chemotherapy (EORTC 08021/ ILCP 01/03). Eur J Cancer 47:2331-2340, 2011

35. Johnson BE, Kabbinavar F, Fehrenbacher L, et al: ATLAS: Randomized, double-blind, placebocontrolled, phase IIIB trial comparing bevacizumab therapy with or without erlotinib, after completion of chemotherapy, with bevacizumab for first-line treatment of advanced non-small-cell lung cancer. J Clin Oncol 31:3926-3934, 2013

36. Zhang L, Ma S, Song X, et al: Gefitinib versus placebo as maintenance therapy in patients with locally advanced or metastatic non-small-cell lung cancer (INFORM; C-TONG 0804): A multicentre, double-blind randomised phase 3 trial. Lancet Oncol 13:466-475, 2012

37. Patel JD, Socinski MA, Garon EB, et al: PointBreak: A randomized phase III study of pemetrexed plus carboplatin and bevacizumab followed by maintenance pemetrexed and bevacizumab versus paclitaxel plus carboplatin and bevacizumab followed by maintenance bevacizumab in patients with stage IIIB or IV nonsquamous non-small-cell lung cancer. J Clin Oncol 31:4349-4357, 2013

38. Lee SM, Rudd R, Woll PJ, et al: Randomized double-blind placebo-controlled trial of thalidomide in combination with gemcitabine and Carboplatin in advanced non-small-cell lung cancer. J Clin Oncol 27:5248-5254, 2009

39. Novello S, Bruzzi P, Barone C, et al: Phase III study in stage IV non-small-cell lung cancer patients treated with two courses of cisplatin/gemcitabine followed by a randomization to three additional courses of the same combination or gemcitabine alone. Ann Oncol 18:903-908, 2007

40. Pérol M, Chouaid C, Pérol D, et al: Randomized, phase III study of gemcitabine or erlotinib maintenance therapy versus observation, with predefined second-line treatment, after cisplatingemcitabine induction chemotherapy in advanced non-small-cell lung cancer. J Clin Oncol 30:35163524, 2012

41. Garassino $M C$, Martelli $O$, Broggini $M$, et al: Erlotinib versus docetaxel as second-line treatment of patients with advanced non-small-cell lung cancer and wild-type EGFR tumours (TAILOR): A randomised controlled trial. Lancet Oncol 14:981-988, 2013

42. Shaw AT, Kim DW, Mehra R, et al: Ceritinib in ALK-rearranged non-small-cell lung cancer. N Engl J Med 370:1189-1197, 2014

43. Kim DW, Mehra R, Tan DSW: Ceritinib in advanced anaplastic lymphoma kinase (ALK)rearranged $(A L K+)$ non-small cell lung cancer (NSCLC): Results of the ASCEND-1 trial. J Clin Oncol 32:506s, 2014 (suppl 5s; abstr 8003)

44. Biesma $B$, Wymenga $A N$, Vincent $A$, et al: Quality of life, geriatric assessment and survival in elderly patients with non-small-cell lung cancer treated with carboplatin-gemcitabine or carboplatinpaclitaxel: NVALT-3 a phase III study. Ann Oncol 22:1520-1527, 2011

45. Kim ES, Neubauer M, Cohn A, et al: Docetaxel or pemetrexed with or without cetuximab in recurrent or progressive non-small-cell lung cancer after platinum-based therapy: A phase 3, open-label, randomised trial. Lancet Oncol 14:1326-1336, 2013

46. Ciuleanu $T$, Stelmakh $L$, Cicenas $S$, et al: Efficacy and safety of erlotinib versus chemotherapy in second-line treatment of patients with advanced, non-small-cell lung cancer with poor prognosis (TITAN): A randomised multicentre, open-label, phase 3 study. Lancet Oncol 13:300-308, 2012

47. Lee DH, Park K, Kim JH, et al: Randomized phase III trial of gefitinib versus docetaxel in nonsmall cell lung cancer patients who have previously received platinum-based chemotherapy. Clin Cancer Res 16:1307-1314, 2010

48. Shi $Y$, Zhang $L$, Liu $X$, et al: Icotinib versus gefitinib in previously treated advanced non-smallcell lung cancer (ICOGEN): a randomised, doubleblind phase 3 non-inferiority trial. Lancet Oncol 14: 953-961, 2013

49. Sun JM, Lee KH, Kim SW, et al: Gefitinib versus pemetrexed as second-line treatment in patients with nonsmall cell lung cancer previously treated with platinum-based chemotherapy (KCSG-
LU08-01): An open-label, phase 3 trial. Cancer 118: 6234-6242, 2012

50. Herbst RS, Ansari R, Bustin F, et al: Efficacy of bevacizumab plus erlotinib versus erlotinib alone in advanced non-small-cell lung cancer after failure of standard first-line chemotherapy (BeTa): A double-blind, placebo-controlled, phase 3 trial. Lancet 377:1846-1854, 2011

51. Natale RB, Thongprasert S, Greco FA, et al: Phase III trial of vandetanib compared with erlotinib in patients with previously treated advanced nonsmall-cell lung cancer. J Clin Oncol 29:1059-1066, 2011

52. Georgoulias V, Androulakis N, Kotsakis A, et al: Docetaxel versus docetaxel plus gemcitabine as front-line treatment of patients with advanced nonsmall cell lung cancer: A randomized, multicenter phase III trial. Lung Cancer 59:57-63, 2008

53. Quoix E, Zalcman G, Oster JP, et al: Carboplatin and weekly paclitaxel doublet chemotherapy compared with monotherapy in elderly patients with advanced non-small-cell lung cancer: IFCT-0501 randomised, phase 3 trial. Lancet 378:1079-1088, 2011

54. Solomon BJ, Mok T, Kim DW, et al: First-line crizotinib versus chemotherapy in ALK-positive lung cancer. N Engl J Med 371:2167-2177, 2014

55. Zukin M, Barrios CH, Pereira JR, et al: Randomized phase III trial of single-agent pemetrexed versus carboplatin and pemetrexed in patients with advanced non-small-cell lung cancer and Eastern Cooperative Oncology Group performance status of 2. J Clin Oncol 31:2849-2853, 2013

56. Shaw AT, Kim DW, Nakagawa K, et al: Crizotinib versus chemotherapy in advanced ALKpositive lung cancer. N Engl J Med 368:2385-2394, 2013

57. Garon EB, Ciuleanu TE, Arrieta O: Ramucirumab plus docetaxel versus placebo plus docetaxel for second-line treatment of stage IV non-small-cell lung cancer after disease progression on platinumbased therapy (REVEL): A multicentre, double-blind, randomised phase 3 trial. Lancet 384:665-673, 2014

58. Morabito A, Gebbia V, Di Maio M, et al: Randomized phase III trial of gemcitabine and cisplatin vs. gemcitabine alone in patients with advanced non-small cell lung cancer and a performance status of 2: The CAPPA-2 study. Lung Cancer 81:77-83, 2013

59. Keedy VL, Temin S, Somerfield MR, et al: American Society of Clinical Oncology provisional clinical opinion: Epidermal growth factor receptor (EGFR) mutation testing for patients with advanced non-small-cell lung cancer considering first-line EGFR tyrosine kinase inhibitor therapy. J Clin Oncol 29:2121-2127, 2011

60. Thongprasert S, Duffield E, Saijo N, et al: Health-related quality-of-life in a randomized phase III first-line study of gefitinib versus carboplatin/ paclitaxel in clinically selected patients from Asia with advanced NSCLC (IPASS). J Thorac Oncol 6:1872-1880, 2011

61. Mok TS, Wu YL, Thongprasert $S$, et al: Gefitinib or carboplatin-paclitaxel in pulmonary adenocarcinoma. N Engl J Med 361:947-957, 2009

62. Ramlau R, Gorbunova V, Ciuleanu TE, et al: Aflibercept and docetaxel versus docetaxel alone after platinum failure in patients with advanced or metastatic non-small-cell lung cancer: A randomized, controlled phase III trial. J Clin Oncol 30:36403647, 2012

63. Herbst RS, Sun $Y$, Eberhardt WE, et al: Vandetanib plus docetaxel versus docetaxel as second-line treatment for patients with advanced non-small-cell lung cancer (ZODIAC): A double-blind, 
randomised, phase 3 trial. Lancet Oncol 11:619-626, 2010

64. Reck $M$, Kaiser $R$, Mellemgaard $A$, et al: Docetaxel plus nintedanib versus docetaxel plus placebo in patients with previously treated nonsmall-cell lung cancer (LUME-Lung 1): A phase 3, double-blind, randomised controlled trial. Lancet Oncol 15:143-155, 2014

65. Scagliotti GV, Krzakowski M, Szczesna A, et al: Sunitinib plus erlotinib versus placebo plus erlotinib in patients with previously treated advanced non-small-cell lung cancer: A phase III trial. J Clin Oncol 30:2070-2078, 2012

66. Lee JS, Hirsh V, Park K, et al: Vandetanib versus placebo in patients with advanced nonsmall-cell lung cancer after prior therapy with an epidermal growth factor receptor tyrosine kinase inhibitor: A randomized, double-blind phase III trial (ZEPHYR). J Clin Oncol 30:1114-1121, 2012

67. Pallis AG, Agelaki S, Agelidou A, et al: A randomized phase III study of the docetaxel/carboplatin combination versus docetaxel single-agent as second line treatment for patients with advanced/ metastatic non-small cell lung cancer. BMC Cancer 10:633, 2010

68. Scagliotti GV, Parikh P, von Pawel J, et al: Phase III study comparing cisplatin plus gemcitabine with cisplatin plus pemetrexed in chemotherapynaive patients with advanced-stage non-small-cell lung cancer. J Clin Oncol 26:3543-3551, 2008

69. Tan EH, Rolski J, Grodzki T, et al: Global Lung Oncology Branch Trial 3 (GLOB3): Final results of a randomised multinational phase III study alternating oral and i.v. vinorelbine plus cisplatin versus docetaxel plus cisplatin as first-line treatment of advanced non-small-cell lung cancer. Ann Oncol 20: 1249-1256, 2009

70. Rodrigues-Pereira J, Kim JH, Magallanes M, et al: A randomized phase 3 trial comparing pemetrexed/carboplatin and docetaxel/carboplatin as first-line treatment for advanced, nonsquamous non-small cell lung cancer. J Thorac Oncol 6:19071914, 2011

71. Lynch TJ, Patel T, Dreisbach L, et al: Cetuximab and first-line taxane/carboplatin chemotherapy in advanced non-small-cell lung cancer: Results of the randomized multicenter phase III trial BMS099. $\mathrm{J}$ Clin Oncol 28:911-917, 2010

72. Okamoto I, Yoshioka H, Morita $\mathrm{S}$, et al: Phase III trial comparing oral S-1 plus carboplatin with paclitaxel plus carboplatin in chemotherapynaive patients with advanced non-small-cell lung cancer: Results of a West Japan Oncology Group study. J Clin Oncol 28:5240-5246, 2010

73. Treat JA, Gonin R, Socinski MA, et al: A randomized, phase III multicenter trial of gemcitabine in combination with carboplatin or paclitaxel versus paclitaxel plus carboplatin in patients with advanced or metastatic non-small-cell lung cancer. Ann Oncol 21:540-547, 2010

74. Kubota K, Kawahara M, Ogawara M, et al: Vinorelbine plus gemcitabine followed by docetaxe versus carboplatin plus paclitaxel in patients with advanced non-small-cell lung cancer: A randomised, open-label, phase III study. Lancet Oncol 9:11351142, 2008

75. Kosmidis PA, Fountzilas G, Eleftheraki AG, et al: Paclitaxel and gemcitabine versus paclitaxel and vinorelbine in patients with advanced non-small-cell lung cancer: A phase III study of the Hellenic Cooperative Oncology Group (HeCOG). Ann Oncol 22: 827-834, 2011

76. Reck $M$, von Pawel J, Zatloukal $P$, et al: Overall survival with cisplatin-gemcitabine and bev- acizumab or placebo as first-line therapy for nonsquamous non-small-cell lung cancer: Results from a randomised phase III trial (AVAiL). Ann Oncol 21: 1804-1809, 2010

77. Blackhall F, Peters S, Kerr Kea: Prevalence and cinical outcomes for patients with ALK gene rearrangment in Europe: Preliminary results for the European Thoracic Oncology Platform Lungscape Project. Ann Oncol 23:ix73-ix94, 2012 (abstr 1670)

78. Shaw AT, Ou SH, Bang YJ, et al: Crizotinib in ROS1-rearranged non-small-cell lung cancer. N Engl J Med 371:1963-1971, 2014

79. Karampeazis A, Vamvakas L, Agelidou A, et al: Docetaxel vs. vinorelbine in elderly patients with advanced non-small-cell lung cancer: A Hellenic Oncology Research Group randomized phase III study. Clin Lung Cancer 12:155-160, 2011

80. Groen HJ, Sietsma H, Vincent A, et al: Randomized, placebo-controlled phase III study of docetaxel plus carboplatin with celecoxib and cyclooxygenase-2 expression as a biomarker for patients with advanced non-small-cell lung cancer: The NVALT-4 study. J Clin Oncol 29:4320-4326, 2011

81. Ridolfi L, Bertetto $O$, Santo $A$, et al: Chemotherapy with or without low-dose interleukin-2 in advanced non-small cell lung cancer: Results from a phase III randomized multicentric trial. Int J Oncol 39:1011-1017, 2011

82. Chang JW, Tsao TC, Yang CT, et al: A randomized study of gemcitabine plus cisplatin and vinorelbine plus cisplatin in patients with advanced non-small-cell lung cancer. Chang Gung Med J 31: 559-566, 2008

83. Non-Small Cell Lung Cancer Collaborative Group: Chemotherapy and supportive care versus supportive care alone for advanced non-small cell lung cancer. Cochrane Database Syst Rev 5:CD007309, 2010

84. Sargent DJ, Köhne $\mathrm{CH}$, Sanoff $\mathrm{HK}$, et al: Pooled safety and efficacy analysis examining the effect of performance status on outcomes in nine first-line treatment trials using individual data from patients with metastatic colorectal cancer. J Clin Oncol 27:1948-1955, 2009

85. Chansky K, Mack P, Crowley J, et al: Chemotherapy outcomes by histologic subtype of nonsmall cell lung cancer (NSCLC): Analysis of the SWOG database for antimicrotubule-platinum therapy. J Thorac Oncol 4, 2009 (suppl 1; abstr B2.7)

86. National Cancer Institute: FDA approval for afatinib dimaleate. http://www.cancer.gov/cancertopics/ druginfo/fda-afatinibdimaleate

87. Soda $M$, Choi $Y L$, Enomoto $M$, et al: Identification of the transforming EML4-ALK fusion gene in non-small-cell lung cancer. Nature 448:561-566, 2007

88. Rikova K, Guo A, Zeng Q, et al: Global survey of phosphotyrosine signaling identifies oncogenic kinases in lung cancer. Cell 131:1190-1203, 2007

89. Camidge DR, Doebele RC: Treating ALKpositive lung cancer: Early successes and future challenges. Nat Rev Clin Oncol 9:268-277, 2012

90. Rossi G, Cavazza A, Marchioni $A$, et al: Role of chemotherapy and the receptor tyrosine kinases KIT, PDGFRalpha, PDGFRbeta, and Met in large-cell neuroendocrine carcinoma of the lung. J Clin Oncol 23:8774-8785, 2005

91. Murray N: Reality check for pemetrexed and maintenance therapy in advanced non-small-cell lung cancer. J Clin Oncol 32:482-483, 2014

92. Paz-Ares LG, de Marinis F, Visseren-Grul C, et al: Reply to S. Barni et al, K.R. Dearing et al, and N. Murray. J Clin Oncol 32:483-485, 2014
93. Karampeazis A, Voutsina A, Souglakos J, et al: Pemetrexed versus erlotinib in pretreated patients with advanced non-small cell lung cancer: A Hellenic Oncology Research Group (HORG) randomized phase 3 study. Cancer 119:2754-2764, 2013

94. Gridelli C, Ciardiello F, Gallo C, et al: First-line erlotinib followed by second-line cisplatin-gemcitabine chemotherapy in advanced non-small-cell lung cancer: The TORCH randomized trial. J Clin Oncol 30:3002-3011, 2012

95. Di Maio M, Chiodini $P$, Georgoulias $V$, et al: Meta-analysis of single-agent chemotherapy compared with combination chemotherapy as secondline treatment of advanced non-small-cell lung cancer. J Clin Oncol 27:1836-1843, 2009

96. de Boer $\mathrm{RH}$, Arrieta Ó, Yang $\mathrm{CH}$, et al: Vandetanib plus pemetrexed for the second-line treatment of advanced non-small-cell lung cancer: A randomized, double-blind phase III trial. J Clin Oncol 29:1067-1074, 2011

97. Krzakowski M, Ramlau R, Jassem J, et al: Phase III trial comparing vinflunine with docetaxel in second-line advanced non-small-cell lung cancer previously treated with platinum-containing chemotherapy. J Clin Oncol 28:2167-2173, 2010

97a. US Food and Drug Administration: Highlights of prescribing information: CYRAMZATM (ramucirumab). http://www.accessdata.fda.gov/ drugsatfda_docs/label/2014/125477s007lbl.pdf

98. Rizvi NA, Mazières J, Planchard D, et al: Activity and safety of nivolumab, an anti-PD-1 immune checkpoint inhibitor, for patients with advanced, refractory squamous non-small-cell lung cancer (CheckMate 063): A phase 2, single-arm trial. Lancet Oncol 16:257-265, 2015

99. US Food and Drug Administration: Nivolumab. http://www.fda.gov/Drugs/InformationOnDrugs/ ApprovedDrugs/ucm427807.htm

100. US Food and Drug Administration: Highlights of prescribing information: OPDIVO ${ }^{\mathrm{TM}}$ (nivolumab). http:// www.accessdata.fda.gov/drugsatfda_docs/label/2015/ 125527s000lbl.pdf

101. Brahmer J, Reckamp KL, Baas $P$, et al: Nivolumab versus docetaxel in advanced squamouscell non-small-cell lung cancer. N Engl J Med 373: 123-135, 2015

102. Gridelli $C$, Maione $P$, Rossi A: The PARAMOUNT trial: A phase III randomized study of maintenance pemetrexed versus placebo immediately following induction first-line treatment with pemetrexed plus cisplatin for advanced nonsquamous non-small cell lung cancer. Rev Recent Clin Trials 8:23-28, 2013

102a. Mok T, Wu Y, Nakagawa K, et al: Gefitinib/ chemotherapy vs. chemotherapy in epidermal growth factor receptor (EGFR) mutation-positive non-small-cell lung cancer (NSCLC) after progression on first-line gefitinib: The phase III, randomised IMPRESS study. Ann Oncol 25, 2014 (abstr LBA2)

102b. US Food and Drug Administration: Ceritinib. http://www.fda.gov/Drugs/InformationOnDrugs/ ApprovedDrugs/ucm395386.htm

103. Gade G, Venohr I, Conner D, et al: Impact of an inpatient palliative care team: A randomized control trial. J Palliat Med 11:180-190, 2008

104. Brumley $R$, Enguidanos $S$, Jamison $P$, et al: Increased satisfaction with care and lower costs: Results of a randomized trial of in-home palliative care. J Am Geriatr Soc 55:993-1000, 2007

105. Finn JW, Pienta, Kenneth J, et al: Hospice of Michigan, Detroit; University of Michigan Comprehensive Cancer Center, Ann Arbor, MI. Proc Am Soc Clin Oncol 21:154s, 2002 (suppl; abstr 1452)

106. Zimmermann $C$, Swami N, Krzyzanowska M, et al: Early palliative care for patients with advanced 
cancer: A cluster-randomised controlled trial. Lancet 383:1721-1730, 2014

107. Bakitas M, Lyons KD, Hegel MT, et al: Effects of a palliative care intervention on clinical outcomes in patients with advanced cancer: The Project ENABLE II randomized controlled trial. JAMA 302:741-749, 2009

108. Temel JS, Greer JA, Muzikansky A, et al: Early palliative care for patients with metastatic non-small-cell lung cancer. N Engl J Med 363:733742, 2010

109. Bakitas M, Tosteson $T$, Li Z, et al: The ENABLE III randomized controlled trial of concurrent palliative oncology care. J Clin Oncol 32:605s, 2014 (suppl 5s; abstr 9512)

110. Lee YJ, Yang JH, Lee JW, et al: Association between the duration of palliative care service and survival in terminal cancer patients. Support Care Cancer 23:1057-1062, 2014

111. Roeland $E$, Loprinzi $C$, Moynihan $T J$, et al: In chemotherapy for lung cancer, sometimes less is more. J Natl Compr Canc Netw 11:232-235, 2013

112. Parikh RB, Kirch RA, Smith $T J$, et al: Early specialty palliative care: Translating data in oncology into practice. N Engl J Med 369:2347-2351, 2013

113. Azzoli $C$, Baker $S$ Jr, Temin $S$, et al: American Society of Clinical Oncology clinical practice guideline update on chemotherapy for stage IV non-small-cell lung cancer (unabridged). http://www.asco.org/sites/ www.asco.org/files/nsclc_unabridged_11.23.09_1.pdf

114. Krakauer $\mathrm{E}$ : Integration of in palliative care in low and middle income countries. Presented the American Society of Clinical Oncology Multidisciplinary Cancer Management Course, Hue, Vietnam August 27-28, 2014

115. Cheng MJ, King LM, Alesi ER, et al: Doing palliative care in the oncology office. J Oncol Pract 9:84-88, 2013

116. Hershman $\mathrm{DL}$, Lacchetti $\mathrm{C}$, Dworkin $\mathrm{RH}$, et al: Prevention and management of chemotherapyinduced peripheral neuropathy in survivors of adult cancers: American Society of Clinical Oncology clinical practice guideline. J Clin Oncol 32:1941-1967, 2014

117. Bower JE, Bak K, Berger A, et al: Screening, assessment, and management of fatigue in adult survivors of cancer: An American Society of Clinical Oncology clinical practice guideline adaptation. J Clin Oncol 32:1840-1850, 2014

118. Andersen $B L$, DeRubeis RJ, Berman BS, et al: Screening, assessment, and care of anxiety and depressive symptoms in adults with cancer: An American Society of Clinical Oncology guideline adaptation. J Clin Oncol 32:1605-1619, 2014

119. Connor SR, Pyenson B, Fitch $K$, et al: Comparing hospice and nonhospice patient survival among patients who die within a three-year window. J Pain Symptom Manage 33:238-246, 2007

120. Saito AM, Landrum MB, Neville BA, et al: Hospice care and survival among elderly patients with lung cancer. J Palliat Med 14:929-939, 2011

121. van Vliet $L M$, van der Wall $E$, Plum NM, et al: Explicit prognostic information and reassurance about nonabandonment when entering palliative breast cancer care: Findings from a scripted videovignette study. J Clin Oncol 31:3242-3249, 2013
122. Partridge $A H$, Seah DS, King $T$, et al: Developing a service model that integrates palliative care throughout cancer care: The time is now. J Clin Oncol 32:3330-3336, 2014

123. Pirl WF, Greer JA, Traeger $L$, et al: Depression and survival in metastatic non-small-cell lung cancer: Effects of early palliative care. J Clin Oncol 30:1310-1315, 2012

124. Brown Johnson CG, Brodsky JL, Cataldo JK: Lung cancer stigma, anxiety, depression, and quality of life. J Psychosoc Oncol 32:59-73, 2014

125. Temel JS, Greer JA, Admane S, et al: Longitudinal perceptions of prognosis and goals of therapy in patients with metastatic non-small-cell lung cancer: Results of a randomized study of early palliative care. J Clin Oncol 29:2319-2326, 2011

126. Emanuel EJ: Plan to fix cancer care. http:// opinionator.blogs.nytimes.com/2013/03/23/a-plan-to-fixcancer-care/?_r=0

127. McGuire L: Ourselves and patients who are dying. Pharos 53:6-8, 1990

128. Hayanga AJ, Zeliadt SB, Backhus LM: Residential segregation and lung cancer mortality in the United States. JAMA Surg 148:37-42, 2013

129. Bryant AS, Cerfolio RJ: Impact of race on outcomes of patients with non-small cell lung cancer. J Thorac Oncol 3:711-715, 2008

130. Bergamo C, Lin JJ, Smith $C$, et al: Evaluating beliefs associated with late-stage lung cancer presentation in minorities. J Thorac Oncol 8:12-18, 2013

131. Shugarman LR, Mack $K$, Sorbero $M E$, et al: Race and sex differences in the receipt of timely and appropriate lung cancer treatment. Med Care 47: 774-781, 2009

132. Hardy D, Liu CC, Xia R, et al: Racial disparities and treatment trends in a large cohort of elderly black and white patients with nonsmall cell lung cancer. Cancer 115:2199-2211, 2009

133. Forrest LF, Adams J, Wareham $H$, et al: Socioeconomic inequalities in lung cancer treatment: Systematic review and meta-analysis. PLoS Med 10:e1001376, 2013

134. Erhunmwunsee $L$, Joshi MB, Conlon DH, et al: Neighborhood-level socioeconomic determinants impact outcomes in nonsmall cell lung cancer patients in the southeastern United States. Cancer 118:5117-5123, 2012

135. Yang R, Cheung MC, Byrne MM, et al: Do racial or socioeconomic disparities exist in lung cancer treatment? Cancer 116:2437-2447, 2010

136. Johnson AM, Hines RB, Johnson JA 3rd, et al: Treatment and survival disparities in lung cancer: The effect of social environment and place of residence. Lung Cancer 83:401-407, 2014

137. Slatore CG, Au DH, Gould MK: An official American Thoracic Society systematic review: Insurance status and disparities in lung cancer practices and outcomes. Am J Respir Crit Care Med 182: 1195-1205, 2010

138. Rasco DW, Yan J, Xie $Y$, et al: Looking beyond Surveillance, Epidemiology, and End Results: Patterns of chemotherapy administration for advanced non-small cell lung cancer in a contemporary, diverse population. J Thorac Oncol 5:15291535,2010
139. Mack JW, Chen K, Boscoe FP, et al: Underuse of hospice care by Medicaid-insured patients with stage IV lung cancer in New York and California. J Clin Oncol 31:2569-2579, 2013

140. American Cancer Society: Cancer Facts \& Figures for African Americans 2013-2014. http:// www.cancer.org/acs/groups/content/@epidemiology surveilance/documents/document/acspc-036921.pdf

141. Howlader N, Noone AM, Krapcho M, et al: SEER cancer statistics review, 1975-2011. http:// seer.cancer.gov/csr/1975_2011/

142. Lin JJ, Mhango G, Wall MM, et al: Cultural factors associated with racial disparities in lung cancer care. Ann Am Thorac Soc 11:489-495, 2014

143. Smith CB, Bonomi M, Packer S, et al: Disparities in lung cancer stage, treatment and survival among American Indians and Alaskan Natives. Lung Cancer 72:160-164, 2011

144. Hede K: Drilling down to the causes of racial disparities in lung cancer. J Natl Cancer Inst 102: 1385-1387, 2010

145. American Lung Association: Too Many Cases, Too Many Deaths: Lung Cancer in African Americans. http://www.lung.org/assets/documents/publications/ lung-disease-data/ala-lung-cancer-in-african.pdf

146. Mead $H$, Cartwright-Smith $L$, Jones $K$, et al: Racial and Ethnic Disparities in U.S. Health Care: A Chartbook. New York, NY, Commonwealth Fund, 2008

147. US Cancer Statistics Working Group: United States Cancer Statistics: 1999-2011 Incidence and Mortality Web-based Report. Atlanta, GA, US Department of Health and Human Services, Centers for Disease Control and Prevention and National Cancer Institute, 2014. http://www.cdc.gov/uscs

148. CMS administrative claims data. Chronic Condition Warehouse (CCW). http://ccwdata.org

149. Charlson ME, Pompei $P$, Ales $K L$, et al: $A$ new method of classifying prognostic comorbidity in longitudinal studies: Development and validation. J Chronic Dis 40:373-383, 1987

150. Linn BS, Linn MW, Gurel L: Cumulative illness rating scale. J Am Geriatr Soc 16:622-626, 1968

151. Fillenbaum GG, Smyer MA: The development, validity, and reliability of the OARS multidimensional functional assessment questionnaire. $J$ Gerontol 36:428-434, 1981

152. Piccirillo JF, Costas I, Claybour P: The measurement of comorbidity by cancer registries. J Registry Manage 30:8-14, 2003

153. Patel JD, Hensing TA, Rademaker A, et al: Phase II study of pemetrexed and carboplatin plus bevacizumab with maintenance pemetrexed and bevacizumab as first-line therapy for nonsquamous non-small-cell lung cancer. J Clin Oncol 27:32843289, 2009

154. Jänne PA, Yang JC, Kim DW et al: AZD9291 in EGFR inhibitor-resistant non-small-cell lung cancer. N Engl J Med 372:1689-1699, 2015

155. Sequist LV, Soria JC, Goldman JW, et al: Rociletinib in EGFR-mutated non-small-cell lung cancer. N Engl J Med 372:1700-1709, 2015

156. Garon EB, Rizvi NA, Hui R, et al: Pembrolizumab for the treatment of non-small-cell lung cancer. N Engl J Med 372:2018-2028, 2015 


\section{AUTHORS' DISCLOSURES OF POTENTIAL CONFLICTS OF INTEREST}

Systemic Therapy for Stage IV Non-Small-Cell Lung Cancer: American Society of Clinical Oncology Clinical Practice Guideline Update

The following represents disclosure information provided by authors of this manuscript. All relationships are considered compensated. Relationships are self-held unless noted. I = Immediate Family Member, Inst = My Institution. Relationships may not relate to the subject matter of this manuscript. For more information about ASCO's conflict of interest policy, please refer to www.asco.org/rwc or jco.ascopubs.org/site/ifc.

\section{Gregory A. Masters}

No relationship to disclose

\section{Sarah Temin}

No relationship to disclose

Christopher G. Azzoli

No relationship to disclose

\section{Giuseppe Giaccone}

Consulting or Advisory Role: Boehringer Ingelheim, Clovis, AVEO Pharmaceuticals

\section{Sherman Baker Jr}

No relationship to disclose

\section{Julie R. Brahmer}

Consulting or Advisory Role: Merck KGaA, Bristol-Myers Squibb, Eli Lilly

Research Funding: Bristol-Myers Squibb (Inst), Merck (Inst), AstraZeneca (Inst), Celgene (Inst)

Travel, Accommodations, Expenses: Bristol-Myers Squibb, Merck Other Relationship: Bristol-Myers Squibb

\section{Peter M. Ellis}

Honoraria: Boehringer Ingelheim, Eli Lilly, Roche Consulting or Advisory Role: Boehringer Ingelheim, Eli Lilly, Roche Other Relationship: Celgene

\section{Ajeet Gajra}

Consulting or Advisory Role: Helsinn Therapeutics, Celgene

Research Funding: Celgene, Merck

\section{Nancy Rackear}

No relationship to disclose

Joan H. Schiller

Consulting or Advisory Role: Biodesix, AVEO Pharmaceuticals, Eisai, Genentech/Roche, Synta, Dekkun, ARIAD Pharmaceuticals, Boehringer Ingelheim, Aggenix, Arguile, Clovis Oncology, Genentech, Abbvie, Eli Lilly, Merck

Research Funding: Synta (Inst), Astex Therapeutics (Inst), Sorono/EMD (Inst), Merrimack (Inst), Endocyte (Inst), Synta (Inst), Astex

Therapeutics (Inst), Genentech (Inst), Merrimack (Inst), Novartis (Inst), Synta (Inst), Clovis Oncology (Inst), Johnson \& Johnson (Inst)

Travel, Accommodations, Expenses: Biodesix

Other Relationship: Free to Breathe

Thomas J. Smith

Stock or Other Ownership: United Healthcare

John R. Strawn

No relationship to disclose

David Trent

No relationship to disclose

David H. Johnson

Consulting or Advisory Role: Peloton Therapeutics, miRNA Therapeutics

Other Relationship: miRNA Therapeutics, Peloton Therapeutics 


\section{Acknowledgment}

We thank Eric P. Mininberg, MD, Melony Sorbero, PhD, and the Clinical Practice Guidelines Committee for their thoughtful reviews and insightful comments on this guideline document, and Whitney Lloyd and Nofisat Ismaila for their assistance.

\section{Appendix}

\begin{tabular}{|ll|}
\hline \multicolumn{1}{|c|}{ Committee Member } & Table A1. Guideline Update Committee Membership \\
\hline David H. Johnson, MD, co-chair & Affiliation/Location \\
Gregory A. Masters, MD, co-chair & University of Texas Southwestern Medical Center at Dallas, Dallas, TX \\
Christopher G. Azzoli, MD, steering committee & Helen F. Graham Cancer Center, Newark, DE \\
Giuseppe Giaccone, MD, PhD, steering committee & Massachusetts General Hospital Cancer Center, Boston, MA \\
Sherman Baker Jr, MD & Lombardi Cancer Center, Georgetown University, Washington, DC \\
Julie R. Brahmer, MD & Virginia Commonwealth University, Richmond, VA \\
Peter M. Ellis, MD, PhD & Sidney Kimmel Comprehensive Cancer Center, Johns Hopkins, Baltimore, MD \\
Joan H. Schiller, MD & Juravinski Cancer Centre, Hamilton, Ontario, Canada \\
Thomas J. Smith, MD & University of Texas Southwestern, Dallas, TX \\
David Trent, MD, PGIN representative & Sidney Kimmel Comprehensive Cancer Center, Johns Hopkins, Baltimore, MD \\
Nancy Rackear, patient representative & Virginia Cancer Center, Richmond, VA \\
John R. Strawn, MD, patient representative & Uniting Against Lung Cancer, Fort Lauderdale, FL \\
Sarah Temin, ASCO staff & Houston, TX \\
\hline Abbreviations: ASCO, American Society of Clinical Oncology; PGIN, Practice Guideline Implementation Network. \\
\hline
\end{tabular}

